\title{
Coupling nearshore and aeolian processes: XBeach and Duna process-based
}

\section{models (manuscript submitted to Environmental Modelling and Software)}

\author{
Dano Roelvink*1 and Susana Costas ${ }^{2}$ \\ * Correspondence to d.roelvink@un-ihe.org \\ ${ }^{1}$ IHE Delft Institute for Water Education and Deltares, Delft, the Netherlands \\ ${ }^{2}$ CIMA - University of Algarve, Faro, Portugal
}

\begin{abstract}
A new dune profile model, Duna, is developed and coupled with the existing XBeach model, in which some key improvements allow a much better behaviour of the intertidal beach and the inclusion of structural erosion or accretion through a longshore transport gradient. The model is shown to represent typical behaviour of a beach-dune system in Praia de Faro, Portugal and to be able to simulate processes on a decadal timescale. The model captures a balance between longshore gradients and cross-shore processes in the surf zone, competing effects of moderate conditions and storms in the intertidal area and between build-up by storm waves and aeolian transport on the berm. Vegetation behaviour is shown to play a key role in the development of the shape of the foredunes. The relation between progradation or recession rate and foredune height as often reported in literature is reproduced and explained.
\end{abstract}

Keywords: beach, dune, profile, erosion, recovery, aeolian

Software availability

The XBeach model (Roelvink et al, 2009, 2018) is an open-source model available under GNU Lesser General Public License v2.1 conditions at www.xbeach.org. This platform provides a source code repository, build scripts for Linux, Windows executables of releases and the latest trunk, documentation and user manual, and a user forum. The code is written in Fortran 90/95 and supports NetCDF output and MPI parallelization. Modifications described here related to the bermslope term affecting the swash zone slope and the longshore gradient term Isgrad are part of the trunk version and XBeachX 2018 release.

The Duna model, the coupling script and all related functions are written in Matlab. The code is available under GNU Lesser General Public License v2.1 at https://github.com/danoroelvink/duna.

\section{Introduction}

The first line of defence for many coasts against the impact of storms and rising sea level consists of fragile sandy/clastic features or coastal barriers. These are composed of submerged and emerged elements, which are in general terms governed by hydro- and aerodynamics. Originally, both compartments have been independently explored (Sherman and Bauer, 1993 and references therein). However, the obvious link between the budget of both compartments raised the need for merging efforts, or at least to consider the adjacent compartment when studying the sediment budget of dunes or beaches, and to move forward in developing appropriately parameterized, process-based, numerical models to apply to the beach-dune interaction (Houser, 2009; Sherman and Bauer, 1993). As a practical example of the need for 
such a holistic approach, beach nourishment projects are currently being designed with dune growth as intended side-effect (e.g. Stive et al., 2013), which in turn reinforces the need for integrative approaches that will quantitatively inform about the best long-term strategies.

A major limitation to a full integration relates to the different temporal scales of relevant morphological changes at both compartments. The dynamic response of compartments is time-dependent, and both are modulated in first terms at instantaneous scale. Yet, research focusing on hydrodynamic processes deals with systems that are constantly changing by the continuous shaping produced by the waves. The magnitude of the changes may depend on the magnitude of the events, but the latter are always functioning as far as they find a beach. Alternatively, dunes present in general terms smaller rates of change and recycling because they are regulated by a less competent and persistent agent. They can be vegetated and fixed relatively easily, and because their evolution or change depends on the availability of sand to be blown by the wind, successful events in terms of sediment transport might not be as frequent as wave events.

Research focusing on nearshore morphodynamics attempts to understand the dynamics within the different compartments of a beach, possibly including the foredune as a soft element capable of being eroded by waves, without considering dune growth and recovery mechanisms. The development of nearshore models has focused on understanding and predicting longshore bar behaviour on the one hand, and on dune erosion on the other hand. A semi-empirical, parameterized model such as SBeach (Larson and Kraus, 1991), was able to represent both processes to some extent, but without providing much detail. UNIBEST-TC, a wave-averaged, process-based model, was able to describe bar behaviour on scales of months (Ruessink et al., 2007) to years (Walstra et al., 2012); it however failed to describe dune erosion and had issues around the water line. The XBeach model (Roelvink et al., 2009) resolves infragravity motions and is well able to describe dune erosion and overwashing but is less well validated for the nearshore bar behaviour. Pender and Karunarathna (2013) did manage to represent both erosion and recovery of the beach by calibrating onshore transport processes. The shape of the intertidal beach profile, however, has often posed a problem where failure to represent complex swash processes typically resulted in too mild slopes. A recent heuristic solution to this problem in Roelvink and Costas (2017) allows XBeach simulations to retain the relatively steep slopes often encountered on ocean beaches, without fixing the shoreline. Another important aspect of nearshore models is their ability to capture effects of longshore transport gradients; in 2DH mode this happens automatically; in profile mode the effect can be added by relating the transport gradient to the longshore transport rate itself, allowing profiles to accrete or erode as a whole.

Research focusing on coastal dune dynamics addresses the interaction between dunes and incident winds in order to understand dune growth mechanisms at event scale (DavidsonArnott et al., 2018; Davidson-Arnott and Bauer, 2009; Hesp and Smyth, 2016a, 2017; Hesp et al., 2013; Smith et al., 2017b), and possibly incorporates the emerged beach to account with the sediment supply at meso-scale (Bauer and Davidson-Arnott, 2003; Bauer et al., 2009; Delgado-Fernandez, 2011; Hesp, 1999; Short and Hesp, 1982), but traditionally does not include the actual mechanisms responsible for making that sand available. The development of coastal dune models has focused on predicting the shape of these landforms as a result of their interaction with local winds, vegetation and other supply limiting factors. AEOLIS (Hoonhout and de Vries, 2016) is an alternative solution for simulating aeolian sediment transport in situations where supply-limiting factors (i.e. soil moisture contents, sediment 
sorting and armouring, bed slope effects, air humidity and roughness elements) are important. This approach resolves a multi-fraction aeolian sediment transport to simulate sediment availability rather than parameterizing it through the velocity threshold. However, it does not (yet) include topographic effects on the wind flow. The SAFE-HILL model (van Boxel et al., 1999; van Dijk et al., 1999) is a morphodynamic solution to simulate the evolution of foredunes with two components: a vertical 2D airflow and a sediment transport component. The latter resolves supply limiting factors such as bed slope, moisture and vegetation, promoting the growth of vegetated foredunes and the migration and growth of bare dunes. In addition, the authors found that vegetation height largely determines the shape of the developing features. The Coastal Dune Model or CDM (Durán and Moore, 2013), adapted from Durán and Herrmann (2006), focuses on simulating the vertical growth and progradation of foredunes, resolving the airflow, the sediment transport and the vegetation growth. Limited to cross-shore winds but resolving the horizontal wind field, the authors found that the elevation of coastal dunes depends on their windward slope, which is in turn determined by plant zonation. The dunes act as a topographic barrier that induces a stagnation zone whose magnitude is inversely proportional to the distance at which vegetation can colonize the beach, resulting in steady-state dunes of invariant scale. The limitation in dune dimension imposed by the wind model has been criticized by Davidson-Arnott et al. (2018) who have found that dunes can maintain their vertical growth over time primarily under oblique rather than onshore winds. To overcome limitations imposed by wind models, a big effort has been made adapting very high-resolution computational fluid dynamic models to resolve local wind fields turbulence (Hesp and Smyth, 2016a, 2017; Hesp et al., 2015; Smyth et al., 2013), and eventually potential sediment transport (Smith et al., 2017a; Smith et al., 2017b). However, the latter are limited to the event scale and do not morphodynamically update the topography. It therefore seems that for the situation of relatively longshore uniform dune rows a simpler approach that allows for oblique wind directions would be worth pursuing.

Alternative solutions, aiming at integrating dune and beach dynamics, have been developed that range from very simplified parametric descriptions of cross-shore profiles and transport processes to very high-resolution and complex models. Hanson et al. (2010) and Larson et al. (2016) proposed an adaptation of the empirical model SBeach (Larson and Kraus, 1989) to include not only dune erosion, but also recovery through simplistic solutions that reproduce dune recovery depending on wind intensity and beach dimensions. The simplified description of the profile also assumes the conservation of the dune morphology. Alternatively, highresolution approaches include the cellular model of dune, beach and vegetation development DUBEVEG developed by Keijsers et al. (2016). This model resolves the interaction dune-beach by introducing simple heuristic solutions that allow the development of complex dune morphologies but do not resolve the interaction of the local wind field with the topography. Finally, efforts are underway to develop highly complex process-based models that synchronize the exchange of sediment between the nearshore and the adjacent beach including a series of coupled process-based morphodynamic models to assess beach morphodynamics, wind turbulence, sediment transport, vegetation growth and supply limiting factors to predict daily to decadal changes in 1D or 2D horizontal mode, e.g. the WINDSURF initiative (Moore et al., 2016a).

The objective of the present paper is to explore the behaviour of combined beach and dunes using a hybrid model, XBeach-Duna, which couples beach and dune morphodynamics and includes variable winds in intensity and directions over a beach and dune profile, has sitespecific vegetation growth characteristics and introduces the most relevant factors limiting 
aeolian sediment transport such as bed slope, moisture, grain size variability and vegetation effects. We aim to develop a balanced model that describes subaerial and subaqueous processes and their interactions at similar level of complexity, applying physical process knowledge where possible and heuristic algorithms where necessary.

In section 2 we will start with a description of the model coupler XBeach-Duna, the relevant modifications to XBeach and the full description of the new Duna model. In section 3 we explore the model behaviour through simple but illustrative simulations, highlighting the importance of the wind field response to the dune and the vegetation characteristics. In section 4 we then turn to a field application at Praia de Faro in the south of Portugal, where we calibrate the model based on observed beach and dune behaviour over a two-year, rather windy period. We then describe a series of sensitivity runs illustrating various factors. In section 5 we explore longer-term runs and investigate the relationship between beach retreat/progradation and vertical dune growth. In the discussion section 6 we put our findings in the light of beach/dune behaviour in literature, after which we draw conclusions and propose next steps.

\section{Model description}

\subsection{XBeach-Duna}

The main script XBeach-Duna (written in Matlab) attempts to holistically simulate the adaptation of sandy profiles to changing wave and wind conditions. XBeach-Duna allows the users to choose one of 3 options in XBeach: to resolve wave-averaged equations but neglecting infragravity waves (stationary wave mode); to resolve short wave variations on the wave group scale and the associated long waves (surfbeat mode), or to resolve individual waves using the non-hydrostatic mode, depending on the needs and temporal scale that the user plans to simulate. The idea is that the user will use the stationary wave mode to simulate moderate wave conditions, the surfbeat mode to run storm waves; the non-hydrostatic mode is not applied in this study. Finally, and as the main contribution of this module, the main script can also give the option to the user to run the aeolian component, Duna, to simulate aeolian processes within the beach-dune transition.

For each of the model modes, a file with a series of input conditions is given; an 'events' file specifies the order of the conditions to be simulated.

The different models act on a common profile specified on a fine 'mother grid', but can use their appropriate resolution for efficiency reasons. Before execution of a model, the bed level is interpolated to the local grid; after execution, bed level differences are interpolated back to the mother grid and then applied. This methodology prevents undesired smoothing by repeated interpolations.

In the case of one of the XBeach modes, the main script prepares the input files, executes $X B e a c h$ and retrieves the relevant output from the model; in case Duna is executed this is carried out through a simple function call.

\subsection{XBeach}

XBeach (Roelvink et al., 2018; Roelvink et al., 2009) is a widely used, open-source code originally designed to model the impact of storms on sandy barriers. Over the last decade, important functionality was added, such as the effects of skewness and asymmetry leading to 
onshore transport, quasi-3D undertow and an efficient stationary wave solver, allowing to simulate the evolution of barred profiles in 1D profile or 2DH area mode. In the present application we restrict ourselves to profile mode, though we do take into account oblique wave incidence.

Two important additions are worth mentioning here. The first, applicable in profile mode only, adds to the bed update equation a longshore transport gradient proportional to the longshore transport:

$$
\frac{\partial S_{y}}{\partial y}=\phi S_{y}
$$

Here, $S_{y}$ is the longshore transport rate (varying along the profile) and $\phi$ a coefficient with dimension $1 /$ length. Depending on the sign of the transport and that of $\phi$, this leads to a net erosion or accretion which is distributed along the profile according to the transport distribution.

The second, 'bermslope' addition addresses the fact that, especially for reflective and semireflective beaches, XBeach tends to grossly overpredict erosion at the water line, since it does not resolve the small-scale and highly dynamic swash processes there. While efforts to improve this situation are ongoing using the non-hydrostatic mode, here we apply a pragmatic approach outlined in Roelvink and Costas (2017), where the profile in a very limited area near the water line is 'nudged' towards a given 'bermslope', using an upslope transport process. This simple modification has a dramatic effect on the behaviour of steep beaches and allows the full range of scarping to berm building, maintaining the general shape of the intertidal beach through erosive and accretive sequences; this is essential for the kind of longer-term simulations of beach and dune interaction that we aim for here.

\subsection{Duna Model}

The Duna model, written in Matlab, can function as stand-alone model, or as an additional module to XBeach to reproduce the response of the dune driven by local winds. Local winds are able to transfer sand sourced within the dune system and from the adjacent beach. Duna is a process-based morphodynamic model that includes a wind model component based on Kroy et al. (2002), a sediment transport component based on Bagnold (1936) and Sauermann et al. (2001), a vegetation growth approach loosely based on Durán and Herrmann (2006), as well as the effect of factors limiting sediment transport such as grain size, vegetation, slope and moisture. The model is flexible enough to allow incorporation of further components and factors interfering with the transport of sand by wind in coastal dunes. The module also includes a scheme to represent the stratigraphy of the resultant dune and beach features.

The Duna model simulates the evolution of dunes as a result of input conditions (e.g. wind, vegetation cover, moisture) that can change over time and interact with the dune topography. The model computes and updates the horizontal distribution of the cross-shore and longshore wind velocity, the velocity thresholds of sand movement, the growth and the coverage of the vegetation, and the sediment transport. The results from each time step allow the update of the dune topography and vegetation cover. 


\subsubsection{Wind model}

Effect of topography on wind shear stress distribution

A module to simulate the wind field was included based on the model for the formation and migration of aeolian sand dunes in unidirectional winds proposed by Kroy et al. (2002). It combines an analytical description of the turbulent wind velocity field above the dune with a continuum saltation model that allows for saturation transients in the sand flux. The model provides a qualitative understanding of important features of real dunes, such as their longitudinal shape and aspect ratio, the existence of a minimum dune size, the formation of a slip face. The natural responses of dunes are related to the occurrence of saturation transients which can in turn break the expected scale invariance.

For the cross-shore, 1D case the shear stress distribution can be calculated by:

$$
\frac{\tau(x)}{\tau_{0}}=\alpha \int_{-\infty}^{\infty}\left[\frac{\frac{\partial z_{b}}{\partial x}(x-\xi)}{\pi \xi}+\beta \frac{\partial z_{b}}{\partial x}(x)\right] d \xi
$$

where $\alpha$ and $\beta$ are function of $L / z_{0}$ ( $L$ is the characteristic length of a heap $h(x, 0)$ and $z 0$ is a measure of the surface roughness), $z_{b}[\mathrm{~m}]$ is the profile elevation (Kroy et al., 2002) based on Weng et al. (1991). While the model is simple, it is based on a quasi-2DV approximation of the full 2DV flow profile and shows a slight reduction in speed at the foot of the dune, a peak in shear stress just windward of the crest and a strong reduction in speed in the lee of the crest.

\section{Effect of wind direction}

In addition, to reproduce more realistic cases, Duna includes the influence of different wind directions over the sand transport. For that, the two wind components are explicitly resolved, and it is assumed that the only component affected by the topography is the perpendicular $\left(u_{x}\right)$ as the topography is homogenous in the $y$ direction:

$$
\begin{aligned}
& u_{x}=u_{\infty} \cos \varphi_{\text {wind }} \sqrt{\frac{\tau(x)}{\tau_{0}}} \\
& v_{x}=u_{\infty} \sin \varphi_{\text {wind }}
\end{aligned}
$$

where $\varphi_{\text {wind }}$ is the angle of the wind relative to the beach normal and $\tau(x) / \tau_{0}$ is the shear stress perturbation (obtained from Kroy et al. (2002)). The magnitude of the wind velocity $u_{w}$, responsible for stirring up the sand, is obtained from:

$$
u_{w}=\sqrt{u_{x}^{2}+v_{x}^{2}}
$$



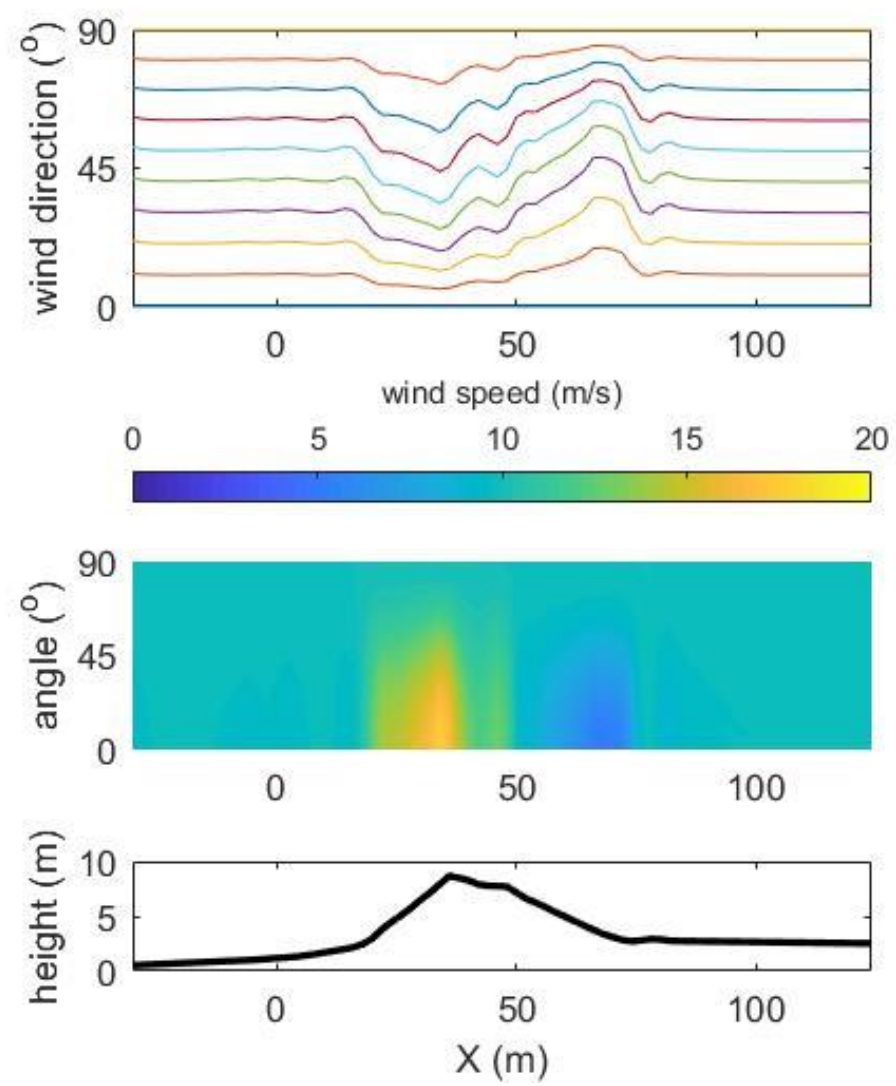

Figure 1. Local wind direction (top panel) and wind speed magnitude (middle panel) as a function of distance along the profile (bottom panel) and the incident wind direction.

The model functioning is illustrated for a case as described in Hesp and Smyth (2016a) for wind at different angles approaching a steep dune profile with a sharp crest. As is shown in Figure 1, the wind magnitude responds in a logical way to the profile and angle of incidence, and significant veering of the flow direction takes place due to the increase resp. decrease of the cross-shore component of the flow.

\section{Lee slope effect}

The wind model does not represent the flow separation behind a sudden drop in height behind a dune. Similar to Kroy et al. (2002) we apply a 'leeslope' effect where a separation bubble area extending below a sloping line with given slope angle is assumed to have no sediment pickup.

\section{Vegetation effect}

The effect of the vegetation on the wind field can be profound. For that two approximations were included;

a) uses the relation proposed by Durán and Moore (2013) through which the impact on the velocity is mostly dependent on the shape of the vegetation and its variability is imposed by changes in the actual height of the plants:

$$
u_{*, v e g}=\frac{u_{*}}{\sqrt{\left(1+\rho_{v} \Gamma\right)}}
$$


where $\rho_{v}$ is the ratio $\left(\frac{h_{v}}{H_{v \max }}\right)^{2}$ or "vegetation factor", which describes the effectiveness of the vegetation in slowing down the flow and thus in trapping sand. Durán and Moore (2013) use $\Gamma=16$ calculated from values of plant form drag and geometry for creosote communities (see Durán and Herrmann (2006) and references therein). It is reasonable to expect a similar value for coastal grasses and desert bushes due to a roughly similar plant geometry). height and $\Gamma$ is a dimensionless "roughness".

b) uses a relation proposed by Buckley (1987) which models the reduction of wind velocity by the vegetation, depending again on its shape. In this case, the changes can be imposed by changing the density of the vegetation cover:

$$
u_{10 v e g}=u_{10}\left(1-\mathrm{k} C_{v}\right)
$$

where $C_{v}$ is the fraction of vegetation cover and $k$ is a constant parameter. For typical small erect or spreading herbaceous dune plants, $k=1.8$, for small rounded stemless plants k=4.6. The tests run by Buckley (1987) were carried out with plant cover $C_{v}$ up to 0.17 . (Note: we use fractions rather than percentages throughout, contrary to some authors).

${ }^{*} C_{v}$ is computed within the vegetation growth section 2.3.3.

The threshold shear velocity $\left(u *_{t}[\mathrm{~m} / \mathrm{s}]\right)$, or the shear velocity needed to initiate the movement, is computed based on Bagnold (1936) by:

$$
u_{* t}=A \sqrt{g d \frac{\rho_{p}-\rho_{a}}{\rho_{a}}}
$$

where $A$ is an empirical constant $(\sim 0.08), \rho_{p}\left[\mathrm{~kg} / \mathrm{m}^{3}\right]$ is the grain density, $\rho_{a}\left[\mathrm{~kg} / \mathrm{m}^{3}\right]$ is the air density, $g\left[\mathrm{~m} / \mathrm{s}^{2}\right]$ is the gravitational acceleration and $d[\mathrm{~m}]$ is the nominal grain size of the sediment fraction. The shear velocity can be transformed into velocity at a certain elevation by applying the law of the wall $\left(u_{t}[\mathrm{~m} / \mathrm{s}]\right)$ at a specific elevation,

$$
u_{t}=\frac{u_{*} t}{\kappa} \ln \frac{z}{z_{0}}
$$

where $\kappa$ is the von Karman constant, $z[\mathrm{~m}]$ is the elevation at which the wind is estimated or measured and $z_{0}[\mathrm{~m}]$ is the height at which the idealized velocity profile reaches zero (i.e. $d / 30)$.

Other limiting factors, apart from the grain size, may also change the threshold velocity, such as the profile slope and the moisture content. Therefore, the threshold shear velocity can be expressed as a function of those factors (the factors included here are the ones introduced so far in Duna).

$$
u_{* t}=f(d, \theta, M)
$$


The effect of those was implemented using different equations. The profile slope $(\theta)$ effect was introduced based on Iversen and Rasmussen (1999). The effect of slope over the threshold friction speed includes the components of the weight parallel and normal to the bed, increasing the threshold friction speed $\left(\mathrm{u}_{\mathrm{t}}\right)$ and decreasing the mass transport (compared with a horizontal bed) if $\theta$ is positive, and to decrease $u_{*_{t}}$ and increase mass transport if $\theta$ is negative.

$$
\frac{u_{*_{t}}^{2}}{u_{*_{t} 0}^{2}}=\cos \theta+\cos \varphi \frac{\sin \theta}{\tan \alpha}
$$

where $\alpha$ is the angle of internal friction of the sediment (repose angle), $\theta$ is the bed slope, $\varphi$ is the wind direction relative to the shore normal (for onshore wind $\varphi=0$ ). The first term on the right-hand side represents a general decrease of the threshold velocity with bed slope, regardless of the wind direction, while the second term accounts for the upslope or downslope increase resp. decrease of the threshold velocity; the $\cos \varphi$ term was added to generalize the equation for use with arbitrary wind directions on a longshore uniform profile.

\section{Moisture content}

Belly (1964) and Johnson (1963) demonstrated that for moisture contents of $0.05-4 \%$, the relationship between fluid threshold velocity and moisture content is logarithmic. The wind tunnel used by Belly was unable to generate wind shears high enough to mobilize sand when the moisture content exceeded $4 \%$. A limiting moisture content of approximately $4 \%$ was also found in studies by Azizov (1977) and Logie (1982).

'Dry' sand normally contains $0.2-0.6 \%$ moisture due to atmospheric humidity (Belly, 1964; Hotta et al., 1985; Tsoar and Zohar, 1985). Experimental and field investigations in Japan (Horikawa et al., 1982; Hotta et al., 1985) suggested a linear, rather than a logarithmic, relationship between fluid threshold velocity and moisture content which is valid for grains in the size range $0.2-0.8 \mathrm{~mm}$ :

$$
u_{*_{\mathrm{tw}}}=u_{*_{t}}+7.5 m
$$

The latter approach was chosen to apply within the Duna model.

As the maximum percentage of volume that water can attain in sandy sediments is $40 \%$, we will have a maximum value (if sediment is water saturated) of $25 \%$ of mass content after applying the following relation:

$$
m=\frac{p_{v} \rho_{w}}{\rho_{s}(1-p)}
$$

where $p$ is the porosity within the sediment, $p_{v}$ is the volumetric water content (percent), $\rho_{w}$ is the sea water density, and $\rho_{s}$ is the sediment density.

If the water content is smaller than 0.0032 (the smaller water content in sediment for dry sand; $0.2 \%$ ), it does not affect the shear velocity threshold. Conversely, values larger than 0.064 of dry weight (or 10\% water content) cease transport (Delgado-Fernandez, 2010), which is implemented as an infinite shear velocity threshold. 
For the particular case of Duna, $m$ is assumed to mainly depend on the humidity derived from the tidal oscillations and swash runup. In addition, a decay function is added to account for the drying of the intertidal beach or a decay in the moisture content with time. The latter is defined by the decay time-scale $\left(T_{m}\right)$ as in:

$$
\frac{\partial m}{\partial t}=-\frac{m}{T_{m}}
$$

\subsubsection{Vegetation growth model}

The vegetation growth (coverage and height) was simulated using a simple algorithm that informs about the equilibrium height or density and growth capacity of the vegetation within one profile as a function of the profile elevation and location within the profile. The equilibrium is introduced by including two parameters; i.e. the maximum vegetation height and coverage; $H_{v \max }$ and $C_{v \max }$ (Table 1 for example).

Table 1. Example of vegetation height and cover maximums based on the profile elevation $\left(z_{b}\right)$

\begin{tabular}{rrrrrr}
$\mathrm{Z}_{\mathrm{b}}$ & -inf & $\mathbf{4 . 0}$ & $\mathbf{5 . 2}$ & $\mathbf{7}$ & +inf \\
\hline $\mathbf{H V}_{\text {vegtab }}$ & 0 & 0.0 & 0.3 & 0.6 & 1 \\
\hline $\mathbf{C V}_{\text {vegtab }}$ & 0 & 0.0 & 0.3 & 0.6 & .9
\end{tabular}

The maximum vegetation values are interpolated from this table; however, where the profile goes down in landward direction, the vegetation is assumed to be at least as high or dense as its seaward neighbour.

Then, the actual elevation of the vegetation $(h v)$ and the coverage vegetation $(c v)$ over the profile are calculated by applying a time scale of vegetation growth $\left(T_{g}\right)$.

$$
\begin{gathered}
\frac{\partial h_{v}}{\partial t}=\frac{H_{v, \text { max }}-h_{v}}{T_{g}} \\
\frac{\partial C_{v}}{\partial t}=\frac{C_{v, \max }-C_{v}}{T_{g}}
\end{gathered}
$$

In case of burial, either by XBeach or by Duna itself, the vegetation height is reduced accordingly, and the density is reduced proportionally with the height reduction. In case of erosion the vegetation height and density increase, at most to their maximum values.

Vegetation dies off when the erosion between successive Duna runs exceeds $0.2 \mathrm{~m}$, or in areas reached by runup. To this end, the maximum runup distance within an XBeach run is stored and passed to the subsequent Duna run. 


\subsubsection{Aeolian sediment transport model}

\section{Transport capacity}

The sediment transport estimates are based on Bagnold (1936), where the sediment transport rate $(Q)$ is calculated by:

$$
Q=\alpha_{1} C \frac{\rho_{a}}{g} \sqrt{\frac{d}{D}}\left(u_{z}-u_{t}\right)^{3}
$$

where $Q[\mathrm{~kg} / \mathrm{m} / \mathrm{s}]$ is the sediment transport capacity, $u_{z}[\mathrm{~m} / \mathrm{s}]$ is the wind velocity at height $z$ $[\mathrm{m}]$ and $u_{t}[\mathrm{~m} / \mathrm{s}]$ the threshold velocity. The properties of the sediment in transport are represented by a series of parameters: $C[-]$ is a parameter to account for the grain size distribution width, $\rho_{a}\left[\mathrm{~kg} / \mathrm{m}^{3}\right]$ is the air density, $g\left[\mathrm{~m} / \mathrm{s}^{2}\right]$ is the gravitational constant, $d[\mathrm{~m}]$ is the nominal grain size and $D[\mathrm{~m}]$ is a reference grain size. $\alpha_{l}$ is a constant to account for the conversion of the measured wind velocity to the near-bed shear velocity. $\alpha_{1}$ can be calculated following Prandtl-Von Karman's Law of the Wall:

$$
\alpha_{1}=\left(\kappa / \ln \frac{z}{z^{\prime}}\right)^{3}
$$

The approach chosen here follows the model introduced by de Vries et al. (2014) and Hoonhout and Vries (2016). The latter calculates aeolian sediment transport rates and sediment exchange with the bed, with the option of varying sediment availability in both space and time. Two parameters representing the sediment concentration (or total load) in air (C $\left[\mathrm{kg} / \mathrm{m}^{2}\right]$ ) are defined: (1) the sediment concentration corresponding to the equilibrium concentration related to wind forcing $\left(C_{u}\right) ;(2)$ the actual sediment concentration $\left(C_{c}\right)$. The sediment exchange is governed by the transport potential and the supply potential which is modelled as the balance between potential deposition $\left(D\left[\mathrm{~kg} / \mathrm{m}_{2} \mathrm{~s}\right]\right)$ and the potential sediment pick up $\left(E\left[\mathrm{~kg} / \mathrm{m}^{2} \mathrm{~s}\right]\right)$.

\section{Equilibrium concentration}

Sediment concentrations in general $(C)$ and sediment transport rates in general $(\mathrm{Q}[\mathrm{kg} / \mathrm{s} / \mathrm{m}])$ are related via:

$$
Q=\zeta u_{w} C
$$

Where $\zeta$ is a factor that accounts for the difference between sediment velocity and the representative wind velocity.

The equilibrium concentration associated with the wind driven sediment transport capacity $\left(Q_{u}\right.$ $[\mathrm{kg} / \mathrm{s} / \mathrm{m}]$ ) can be expressed as a function of wind speed and threshold velocity and simplified using standard coeffients:

$$
Q_{u}=1.5 \times 10^{-4}\left(u_{w}-u_{t}\right)^{3}
$$

Therefore, the corresponding equilibrium sediment concentration $\left(C_{u}\right)$ can be calculated by: 


$$
C_{u}=\frac{Q_{u}}{\zeta u_{w}}
$$

\section{Transport equation}

Due to spatial variations in equilibrium concentration and limited sediment availability the equilibrium sediment concentration is usually not reached everywhere. To represent realistic variations in the actual concentration we calculate it using a one dimensional advection model:

$$
\frac{\partial C_{c}}{\partial t}+\frac{\partial u C_{c}}{\partial x}=E-D
$$

$D\left[\mathrm{~kg} / \mathrm{m}^{2} \mathrm{~s}\right]$ is the deposition and $E\left[\mathrm{~kg} / \mathrm{m}^{2} \mathrm{~s}\right]$ is the erosion. Instead of using explicit functions for pickup and deposition of sediment, for which accurate estimates are lacking, we prefer to use an approach where we link the net exchange with the bottom to the difference between the equilibrium concentration $C_{u}$, for which there are reasonable formulations available, and the actual concentration $C_{c}$, divided by a relaxation timescale $T$. This model is close to that of Sauermann et al. (2001).

$$
\frac{\partial C_{c}}{\partial t}+\frac{\partial u C_{c}}{\partial x}=\frac{\min \left(C_{u}, C_{b}\right)-C_{c}}{T} P
$$

Where $C_{c}$ is actual concentration in suspension, $C_{b}$ is an empirical upper limit of the concentration of approx. $2 \mathrm{~kg} / \mathrm{m}^{2}$ and $T$ is a timescale of order $1 \mathrm{~s}$. $P$ represents the effect of armoring as discussed in the following.

\section{Supply limitation}

Supply limitation can result from an equilibrium concentration that is reduced by moisture, slope effects or vegetation, or it may be the effect of 'armouring'. This effect occurs when a surface of mixed sediments is eroded, where the finer sediment fractions are picked up more easily and the remaining coarse sediments and shell fractions form a surface layer that is difficult to erode and hence mainly acts as a conduit over which finer sediment may be transported in saltation or suspension. The armouring effect can be removed by 'reset' events, such as a swash zone passing over it, extreme wind events or frequent disturbance by beach visitors. Hoonhout and Vries (2016) present a multi-fraction, multiple-layer model that is capable of developing such armouring in a detailed way. Though we could have adopted their model we prefer a simpler approach that still represents the essential behaviour, viz. that the upper beach often gets depleted of transportable sand and acts like a conduit for sand picked up from areas that are regularly reset, such as the intertidal beach. We consider a sediment composition made up of just two fractions: material that is easy to transport under typical aeolian transport events, and much coarser gravel and shell hash that is virtually impossible to move by wind. We are not attempting to gradually develop a detailed vertical grain size distribution, since we expect the beach face and backshore to be reset regularly by waves and people; rather we concentrate on the change in composition of the surface layer, of a thickness in the order of a couple of the larger grainsizes, which we consider to be fully mixed. For a given (small) change of the bed level $\Delta z_{b}$, mixing layer thickness $h_{\text {mix }}$ and volume fraction of the transportable sediment $p_{\text {fine }}$ we can now express the rate of change of that volume fraction as: 


$$
\begin{array}{ll}
\Delta p_{\text {fine }}=\frac{\Delta z_{b}}{h_{\text {mix }}}\left(1-p_{\text {fine, under }}\right), & \Delta z_{b}<0 \\
\Delta p_{\text {fine }} & =\frac{\Delta z_{b}}{h_{\text {mix }}}\left(1-p_{\text {fine }}\right), \quad \Delta z_{b}>0
\end{array}
$$
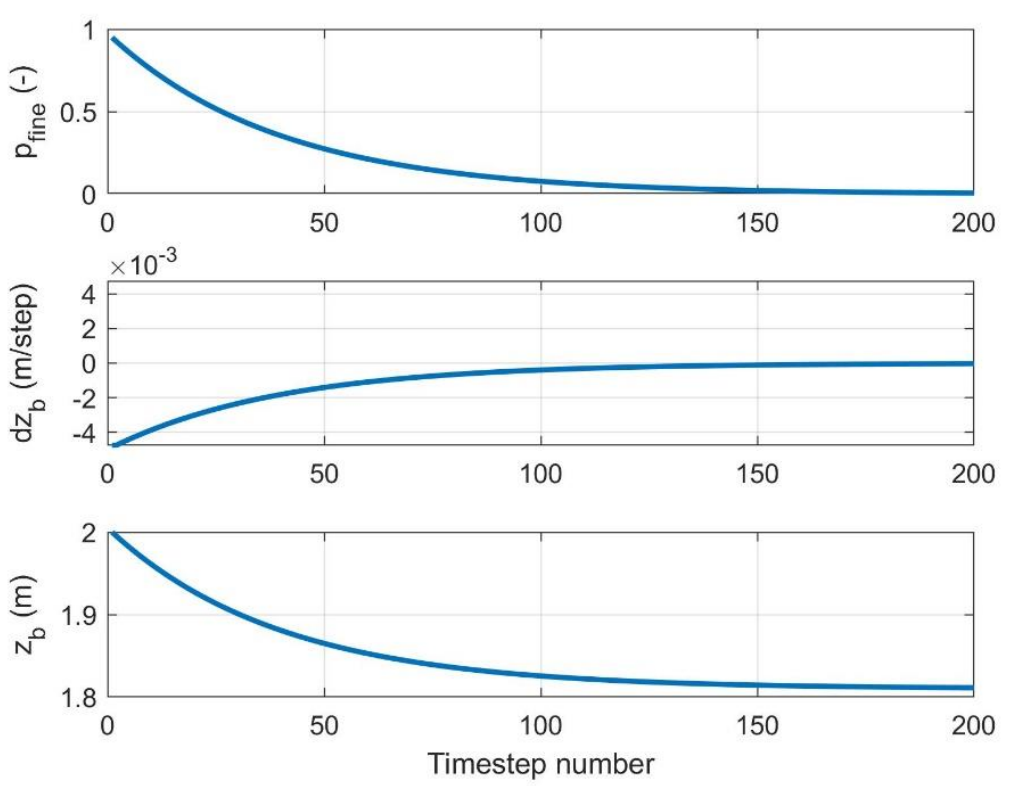

Figure 2. Development of armoring in case of erosion, for an initial fraction of fine sand of 0.95 and potential erosion rate of $5 \mathrm{~mm}$ per time step

When eroding, the mixing layer eats into the underlying material, which is assumed to be constant and uniform; when accreting, the new material only interacts with the existing material in the mixing layer. The process of armouring in the case of erosion is illustrated in Figure 2, which shows how the erosion is progressively reduced as the fine sand fraction is removed from the bottom mixing layer; in case of accretion any initial armouring is removed by the deposition of fine sand and deposition can take place unhindered.

With the fraction of transportable sand at the surface thus given, we can take this into account in the transport equation through the factor $P$ representing the effect of supply limitation (see equation 2.20). This factor depends on whether there is erosion, in which case the exchange term is limited by the availability of the transportable sediment, or accretion, in which case the bottom exchange term is unaffected by the composition of the surface material:

$$
\begin{array}{ll}
P=p_{\text {fine },}, & \min \left(C_{u}, C_{b}\right)-C_{c}>0 \\
P=1, & \min \left(C_{u}, C_{b}\right)-C_{c} \leq 0
\end{array}
$$

\subsubsection{Numerical implementation}

For the numerical implementation we aimed at an extremely robust, implicit upwind scheme, which can handle relatively large time steps. The most critical is the solution of the advection equation. In the fully implicit scheme gradients in the concentration are taken at the new time 
level $n+1$. The index $i$ denotes the location in the grid and $i-1$ signifies the upwind point.

$$
\begin{aligned}
& \frac{C_{c, i}^{n+1}-C_{c, i}^{n}}{\Delta t}+\frac{u_{i} C_{c, i}^{n+1}-u_{i-1} C_{c, i-1}^{n+1}}{\Delta x}=\frac{C_{u, i}-C_{c, i}^{n+1}}{T} \Rightarrow \\
& C_{c, i}^{n+1}\left(\frac{1}{\Delta t}+\frac{u_{i}}{\Delta x}+\frac{1}{T}\right)=\frac{u_{i-1}}{\Delta x} C_{c, i-1}^{n+1}+\frac{C_{c, i}^{n}}{\Delta t}+\frac{C_{u, i}}{T} \Rightarrow \\
& C_{c, i}^{n+1}=\left(\frac{\frac{u_{i-1}}{\Delta x} C_{c, i-1}^{n+1}+\frac{C_{c, i}^{n}}{\Delta t}+\frac{C_{u, i}}{T}}{\left(\frac{1}{\Delta t}+\frac{u_{i}}{\Delta x}+\frac{1}{T}\right)}\right)
\end{aligned}
$$

Here, $C$ is the actual concentration, $C_{u}$ the equilibrium concentration and $T$ the pick-up timescale. The solution progresses from the upwind side to the downwind side. The sediment transport $S_{x}$ is computed as:

$$
S_{x}=C u
$$

For each point $i$ we then compute the bed level change as:

$$
\frac{\partial z_{b, i}}{\partial t}=-\frac{1}{\rho_{s}(1-p)} \frac{S_{x, i}-S_{x, i-1}}{\Delta x}
$$

Here, $p$ is the porosity, $\rho_{s}$ the density of sand and $i-1$ again refers to the upwind point.

\section{Exploration of model behavior}

\subsection{Duna only tests for typical profile}

To explore the behaviour of the model for the wind-only case we take a profile with a Gaussian dune profile, with length scale $25 \mathrm{~m}$ and height of $3 \mathrm{~m}$, on top of an upper beach of $4.5 \mathrm{~m}$ elevation, as is typical for the dunes at Praia de Faro. A representative wind speed is $9.25 \mathrm{~m} / \mathrm{s}$ which we take as a constant. We consider two cases, one without vegetation, and one with a typical distribution of the vegetation. In the first case, we see the initial development in Figure 3. The velocity distribution shows the typical peak just windward of the crest and a reduction behind it; the threshold speed shows a mild influence of the bed slope, where the threshold is raised on the upslope and reduced at the downslope. The equilibrium transport peaks just in front of the crest, but the actual transport, taking into account lags in picking up and settling, is almost in phase with the moving dune, leaving the dune height roughly constant. Where the transport picks up after the minimum behind the dune, the profile is eroded, and a small valley is formed. 

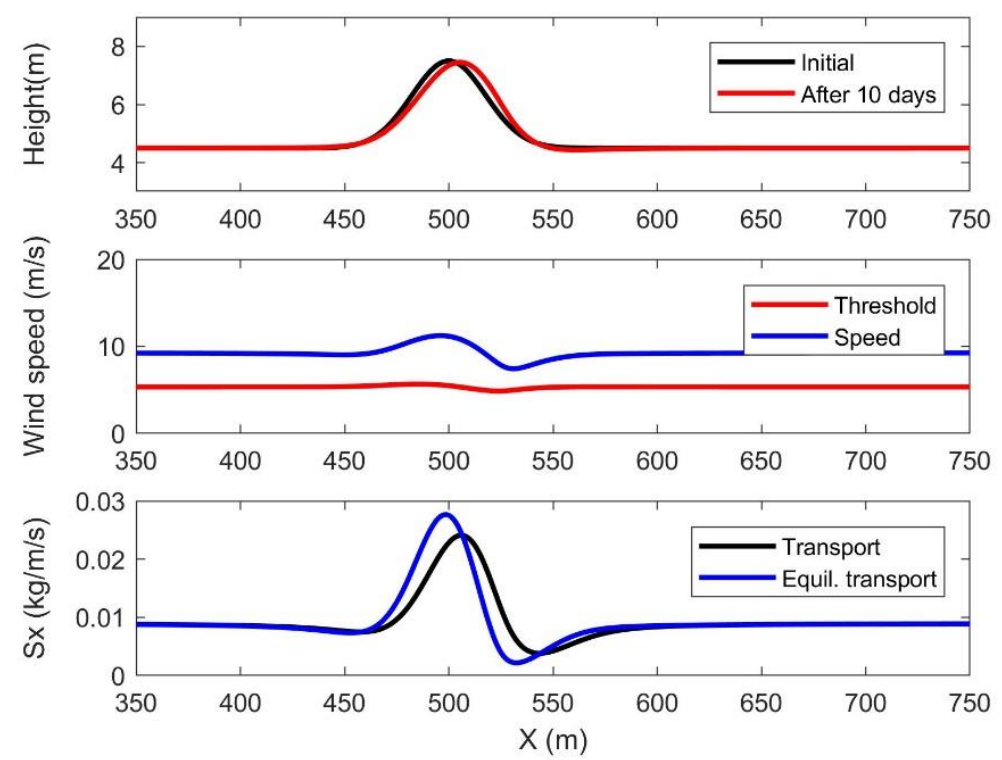

Figure 3. Initial development of a dune profile without vegetation; profile evolution (top panel); wind speed and threshold speed (middle panel); equilibrium transport and actual transport (bottom panel)
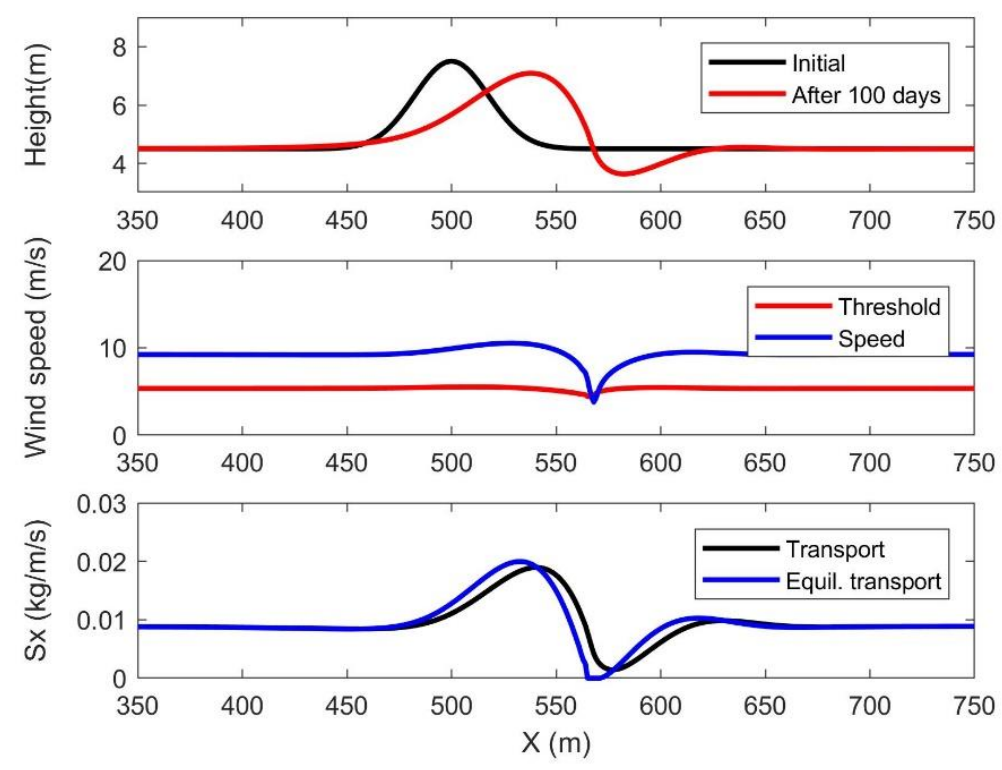

Figure 4. Development after 100 days of a dune profile without vegetation; profile evolution (top panel); wind speed and threshold speed (middle panel); equilibrium transport and actual transport (bottom panel)

After 100 days (Figure 4) the profile has steepened up to the point where the 'leeslope' separation bubble (set at a slope of 1/6) affects the downwind side of the dune, leading the equilibrium transport to be set to zero, though the actual transport does not reach zero before it picks up again. While the mild erosion valley is understandable from a physical point of view, in practice it will not happen often, as either the substrate is unerodible, the groundwater level may be close or vegetation is likely to prevent the picking up of the sediment transport.

To illustrate this, we can simulate the same hump over an unerodible surface; in this case, the suspended transport is limited to the upwind supply if the bottom threatens to go below the 
defined unerodible layer. Figure 5 shows the resulting evolution, where the picking up of new sediment behind the hump is blocked and actual transport becomes constant.
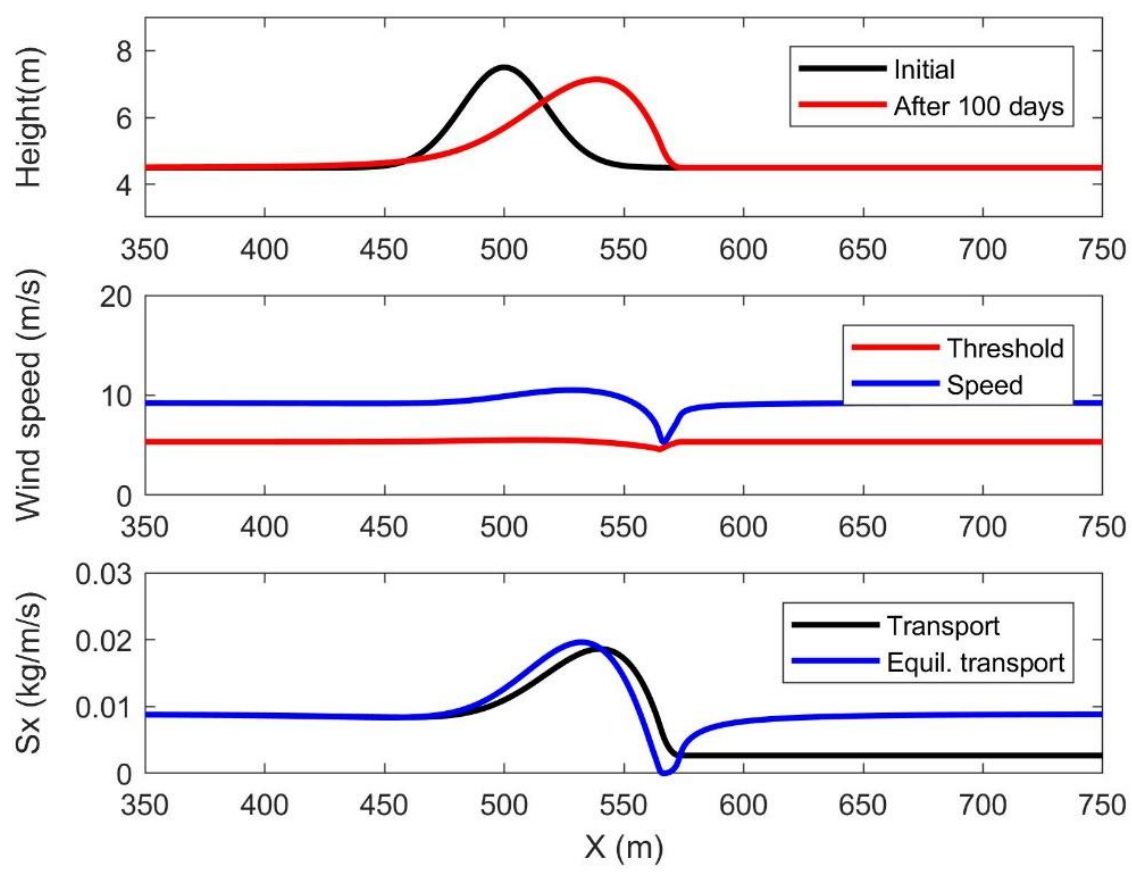

Figure 5. Behavior of the same hump in case of propagation over an unerodible layer.

An entirely different situation occurs if there is vegetation present. In the example we let the equilibrium vegetation cover increase from 0 through 0.3 to 0.6 over heights of $4.5 \mathrm{~m}, 5.2 \mathrm{~m}$ and $7 \mathrm{~m}$, respectively, and set the reduction factor $k$ to 0.9 . As we see, this leads to a reduced wind velocity below the threshold velocity at approx. $7 \mathrm{~m}$ height, which means that no sediment makes it over the top, see Figure 6 . Given this vegetation distribution this leads to a gradual expansion of the dune face. Examples like this show that the distribution of the vegetation is a dominant factor in the evolution of the dune; therefore we will pay most attention to this distribution in the calibration for the field case. 

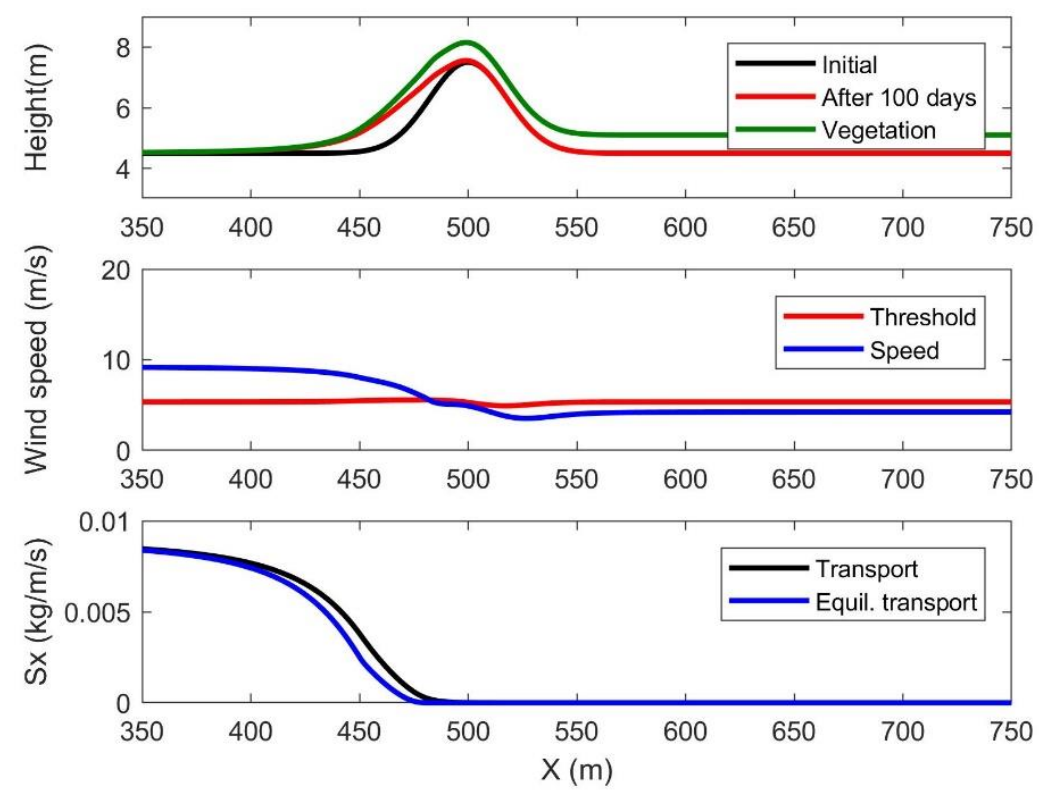

Figure 6. Evolution of a vegetated dune under constant wind conditions

These are just a few examples of the many system tests that were carried out to verify the robustness of the numerical scheme, and whether it is able to handle arbitrary combinations of onshore, offshore and oblique wind conditions. The typical time step applied in the simulations is $2 \mathrm{hrs}$.

\section{Application to Praia de Faro}

Praia de Faro is located within the Ancão Peninsula, at the western flank of the Ria Formosa barrier island system at the southernmost coast of Portugal (Figure 7). It is exposed to the dominant waves approaching the area from W-SW directions with average annual offshore significant wave height of $1.0 \mathrm{~m}$ and an average peak period of $8.2 \mathrm{~s}$ (Costa et al., 2001). Grainsize distribution is relatively heterogeneous with a clear tendency to concentrate coarse to very coarse sands at the beach, and relatively finer sands at the dune (Costas et al., 2018). Morphodynamically, the cross-shore profile has been classified as reflective to intermediate, with the formation of nearshore bars that are rapidly welded to the emerged beach as beach berms. The slope of the beach face is about 0.1, varying from 0.06 to 0.15 (Vousdoukas et al., 2012). Reflective beaches have been traditionally associated with low coastal dunes as a consequence of the aerodynamics at the emerged beach (steep foreshore and sharp berm crests), the relatively coarse sediments, and narrow backshore that typically prevents the formation of high dunes (Hesp, 1988; Hesp and Smyth, 2016b; Sherman and Bauer, 1993; Short and Hesp, 1982). In this line, dunes at Praia de Faro are relatively low, with elevations usually $3 \mathrm{~m}$ above the high berm (which is at approx. $4 \mathrm{~m}$ above MSL). Lower berms can be built at Praia de Faro depending on the magnitude of the run up and the tides, however those do not usually leave a permanent signal within the profile. 


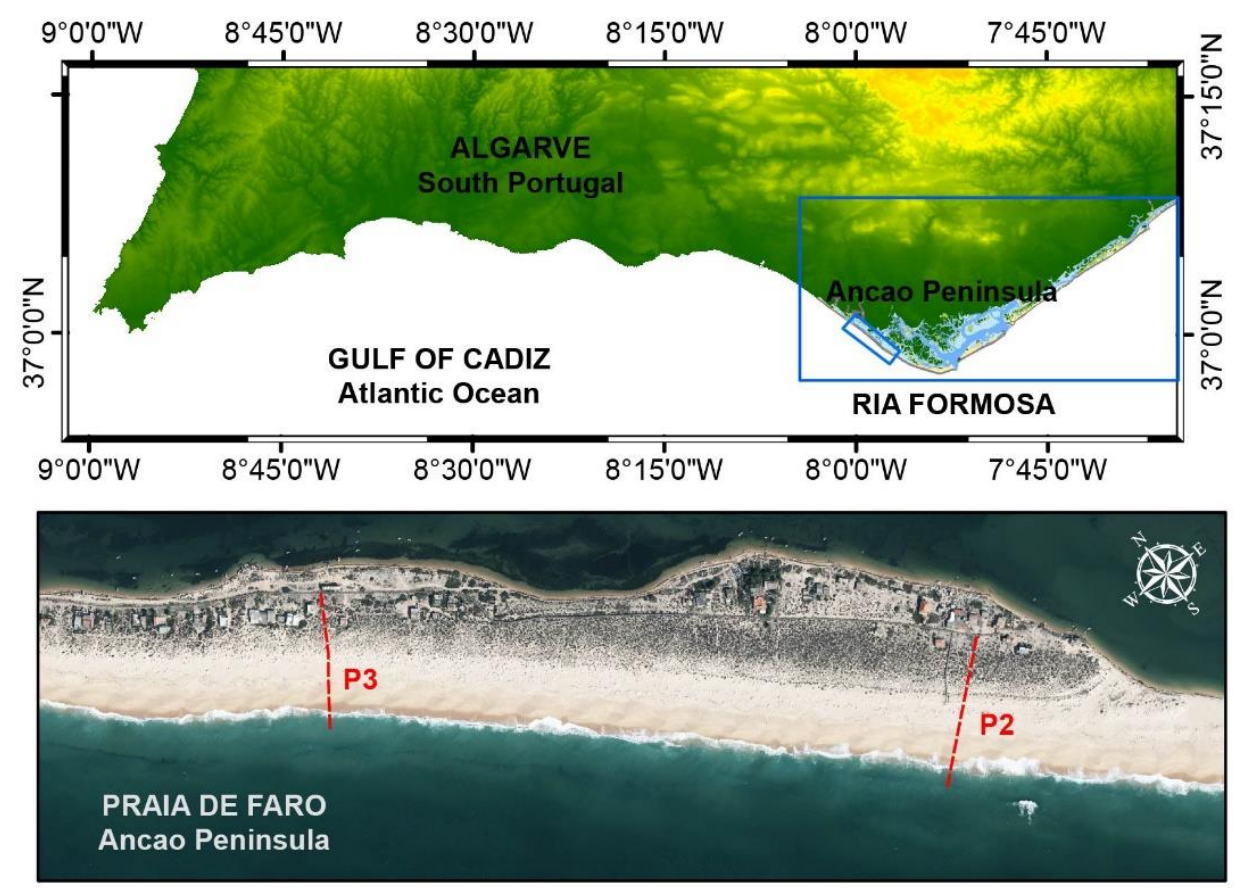

Figure 7. Site location, large scale (top panel) and detail with profile P2 and P3 locations at Praia de Faro, Ancão Peninsula.

For testing the approach proposed here, we have selected two cross-shore profiles located at the natural, non-urbanized, area of Praia de Faro, which is represented by a steep foreshore, a backshore with variable width and a vegetated mature dune ridge about $50 \mathrm{~m}$ wide. The profiles were extracted from two LiDAR datasets surveyed in November 2009 and 2011. Unfortunately, the survey carried out in 2009 did not cover the submerged beach and thus we lack the underwater profile for 2009. To overcome this limitation, we have extended the profiles by assuming an average underwater profile with support from previous data from Praia de Faro (Almeida et al., 2011). The authors document the cross-shore morphological variability of the profile, identifying zones of change within the active profile based on the pattern of vertical variability: the beach face with the formation and erosion of berms, the subtidal terrace with trough/bar generation between 1.5 and $4 \mathrm{~m}$ below MSL, the long-shore bar located between 4 and $6 \mathrm{~m}$ below MSL and the deeper part of the profile that reaches $10 \mathrm{~m}$ below MSL. Thus, we have elaborated an average shape for the underwater profile with more sediment within the trough zone relative to the observations in 2011 (Figure 8), following a period of enhanced storminess during the winter 2009/2010.
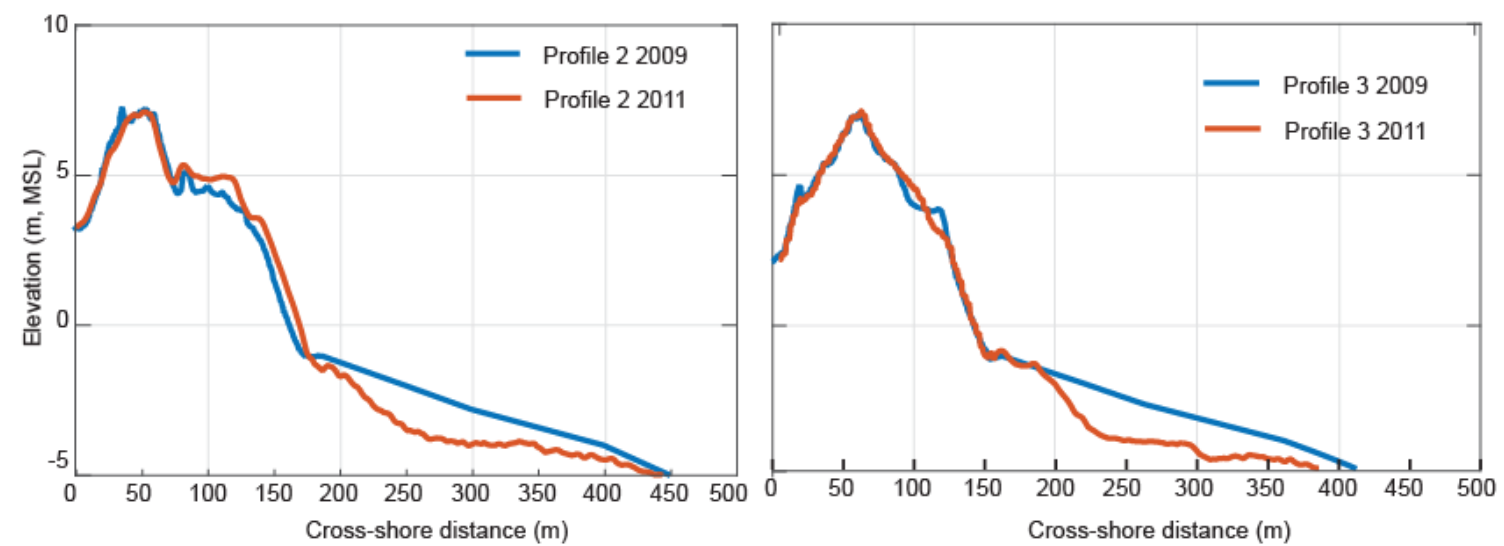

Figure 8. Measured profiles from Praia de Faro. 
The main difference between both profiles is the width of the emerged barrier; profile 2, located within the vicinity of Ancão inlet, is wider and presents an area of active growth with new foredunes and embryo dunes while profile 3 shows a more stable morphology without new space or progradation that prevents the growth of new foredune ridges. In fact, the shoreline at the location of profile 2 has shown a clear prograding trend the last years after the inlet relocation in 1997. For the period of two years analysed here, the beach shows a modest accretion and vertical aggradation of the adjacent embryo and foredune region (Figure 8). On the other hand, profile 3 shows a clearly stable shape, in agreement with the stable location of the shoreline within this area, with a slight aggradation of the dune distributed between the embryo and the mature dune ridge (Figure 8). A close examination of available aerial photographs contemporaneous with the LiDAR surveys allowed us to estimate the distribution of the vegetation cover across the profile, and in particular with the elevation (Figure 9). The cross-shore distribution of vegetation was estimated for each cross-shore meter using a value averaged for a $50 \mathrm{~m}$ longshore polygon. The results show how the vegetation density increases almost linearly with the elevation. The highest values are reached at the crest of the mature dune ridge and they drop slightly across the lee slope. The typical coastal dune plant species in this area belong to the European Biogeographic Region, in particular to the Mediterranean Region. Cakile maritima, Elymus farctus, Eryngium maritimum and Euphoria paralias characterizing the embryo dunes, represented the most tolerant plant association. As we advance inland, the next plant association that we find colonizes the foredunes and is represented by Ammophila arenaria, Lotus criticus, Otanthus maritimus and Crucianella maritima. The latter is followed inland by a new association represented by Artemisia chritmifolia, Armeria pungens, Anthemis maritima and Thymus carnosus, colonizing the mature and fixed dune ridge. In general terms, and contrasting with dunes formed in northern latitudes, grasses do not clearly dominate the vegetation cover in this region.

Sediments in Praia de Faro consist of moderately sorted coarse sands (Costas et al., 2018), suggesting a relatively high degree of grain-size heterogeneity. In fact, Costas et al. (2017) found that the mean grain size at the beach face and dune might be finer that at the backshore, suggesting a concentration of coarser fractions related to swash processes or surface armouring.
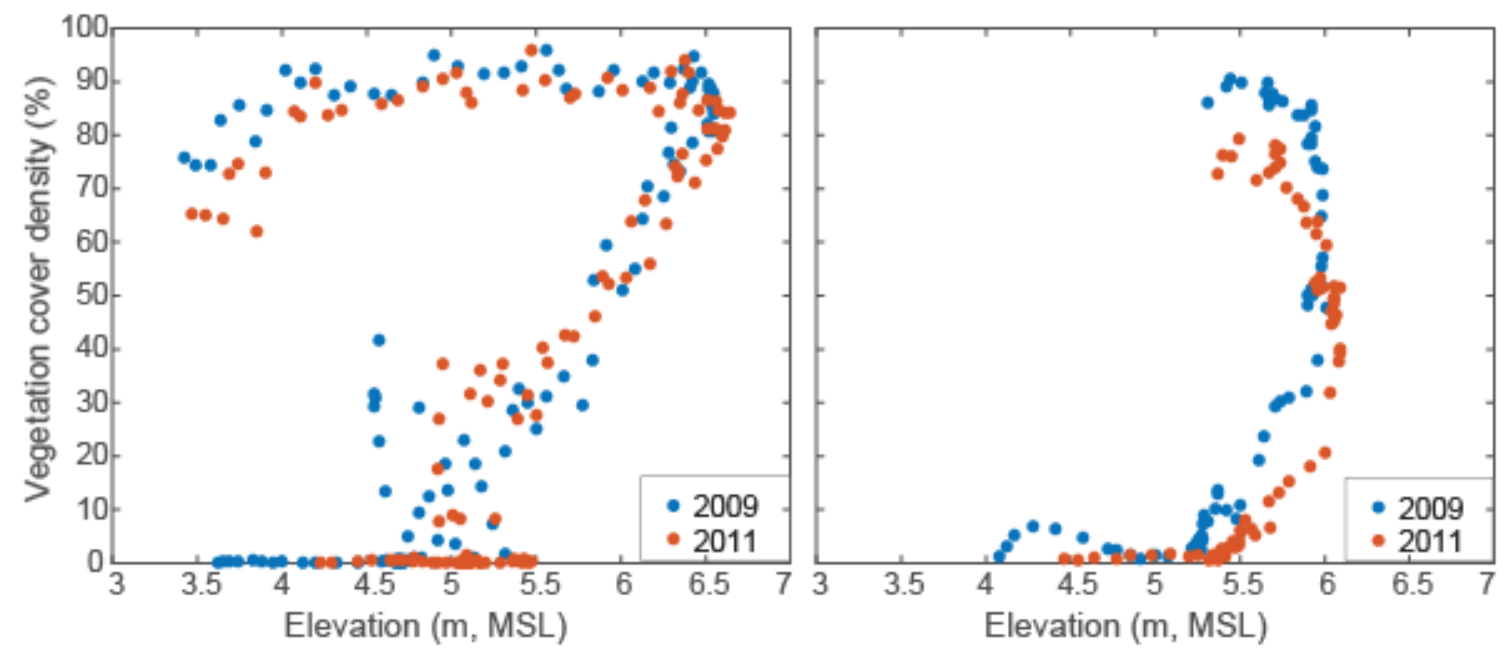

Figure 9. Distribution of the vegetation cover across the profile (profile 2 at the left panel and profile 3 at the right panel). 


\subsection{Wind and wave schematization}

Wind data over the period was available from the meteo station at Faro Airport, located $2 \mathrm{~km}$ inland from the beach and without topographic barriers. Wave data was obtained from a detailed hindcast in the SIMAR database provided by Puertos del Estado-AEMET, Spain (ref SIMAR-5017021, longitude: $8.08^{\circ} \mathrm{W}$, latitude: $37.00^{\circ} \mathrm{N}$ ), see Figure 10 . Especially the winter $2009 / 2010$ was very stormy, with wind speeds up to $19 \mathrm{~m} / \mathrm{s}$ and several events with significant wave height over $4 \mathrm{~m}$ and peak wave periods of $15-20 \mathrm{~s}$. In order to simulate the 2-year period within reasonable runtime, we had to use a schematized wind and wave climate, especially for the computationally intensive XBeach simulations. After some sensitivity runs we found acceptable values for the morphological acceleration factor to be 5 for the surfbeat-mode storm simulations and 25 for the moderate conditions run in stationary mode. The wave conditions covered $95 \%$ of the time, as there is almost always some wave action shaping the beach, whereas the wind speed exceeded the critical wind speed only during 67 days in the 25month period; during the low-wind conditions only the vegetation growth was active and the rest of the Duna model was inactive.

In order to retain the seasonality, we carried out a wind and wave schematization per 3-month season and then put the generated time series together. The percentages of occurrence of wind conditions were collected into $2 \mathrm{~m} / \mathrm{s}, 20^{\circ}$ bins, and average wind speed and direction per bin were saved. The wave conditions were automatically distributed over 4 direction bins and 3 wave height bins, where the distribution over the bins was such that each had roughly the same total energy flux.
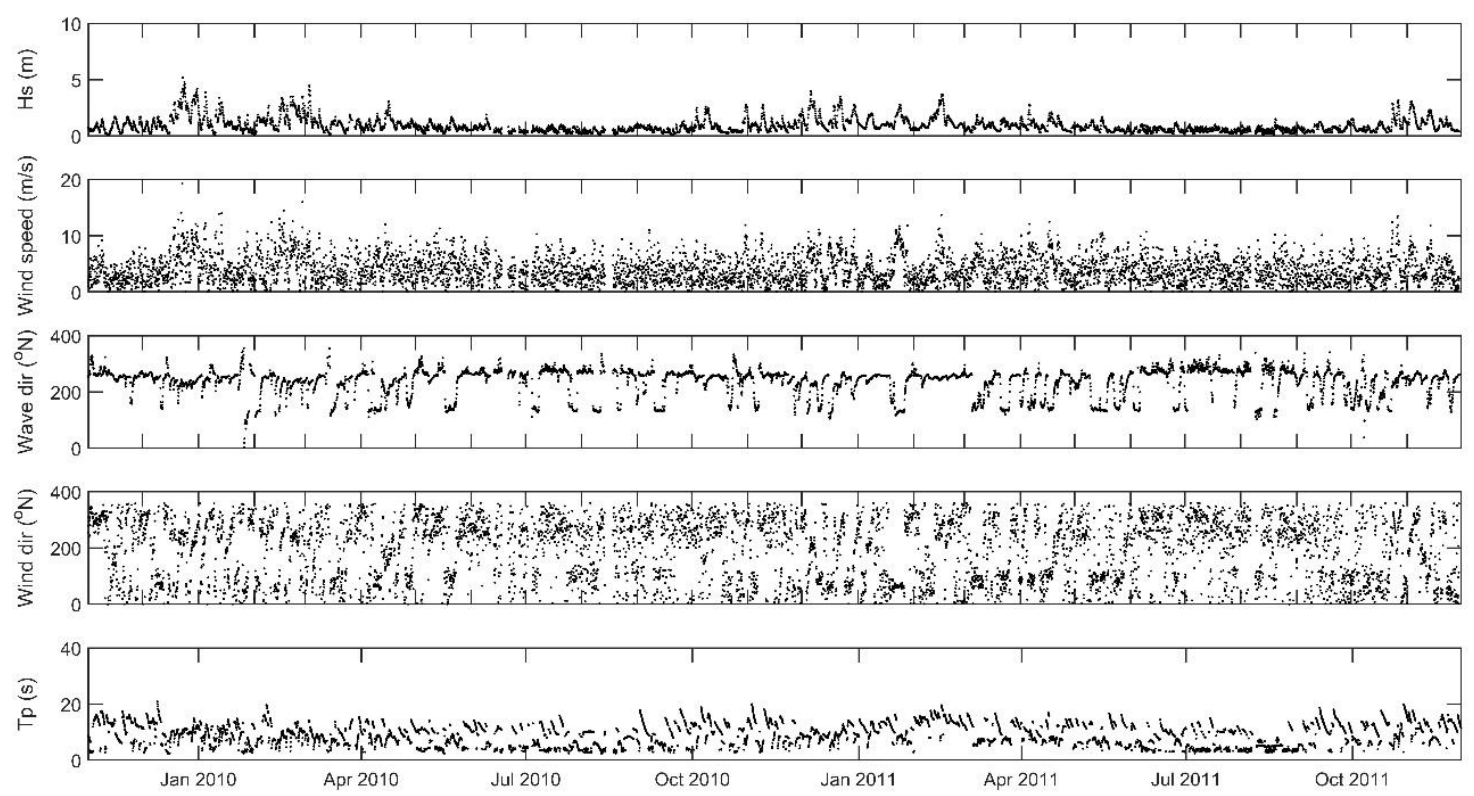

Figure 10. Wind and wave conditions over the period 2009/11/1 till 2011/11/30

An example of this procedure is shown in Figure 11 for the first, most energetic winter of 2009/2010.

The wave conditions with wave height lower than $2 \mathrm{~m}$ were considered to be 'moderate', the ones with higher waves 'storms'. This resulted in tables of wind, moderate and storm wave conditions per season. Finally, an 'events' file was generated that randomly selected wind, 
storm and moderate conditions for each season, such that all conditions were finally selected once.

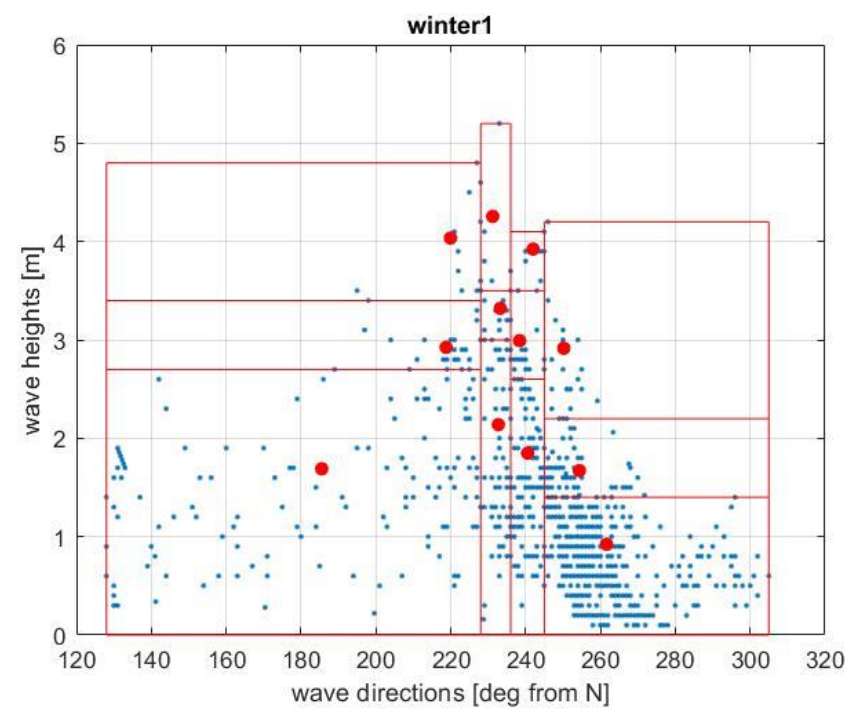

Figure 11. Representative wave conditions for the winter season 2009/2010

The final schematized wind/wave time series is visualized in Figure 12. In total, 53 days are characterized by storms, 67 days have wind above the threshold velocity and the remaining 683 days are moderate conditions.
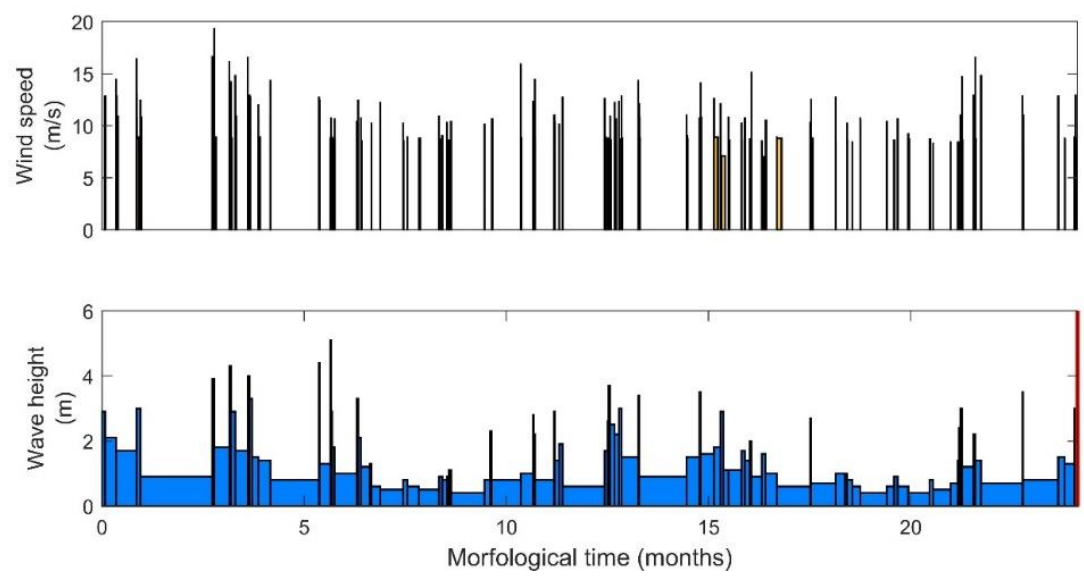

Figure 12. Schematized time series of wind and wave conditions. Top panel: wind speeds; bottom panel: wave heights.

\subsection{Calibration}

First, we have focused on calibrating the beach profile by running the two years of schematized metocean conditions without including longshore gradients in order to force the profile to change but with the objective of identifying the most stable responses; those that allowed the profiles to evolve over time without showing significant changes within their intertidal zone mainly. Of particular interest was to reproduce realistic berms that act as source of sediment towards the dune.

For that, we ran XBeach in an almost default setting, but varying the wave asymmetry parameter to affect the sediment advection velocity (facAs), and thus the rate of sediment 
input onshore. Changes to this parameter were introduced in combination with changes to the value of the bermslope to find the best combination. On the one hand, the values of facAs that were used were 0.35 and 0.40 (values already high as previous results have shown they better adjust the shape of steep/reflective beach profiles (Poelhekke et al., 2016). On the other hand, the values of the bermslope chosen for the calibration were selected for best reproducing the slopes observed at the beach face (values between 0.16 and 0.20 ). The results suggest that the best combination is similar for both profiles, with a value for bermslope of 0.16 performing best (Figure 13).
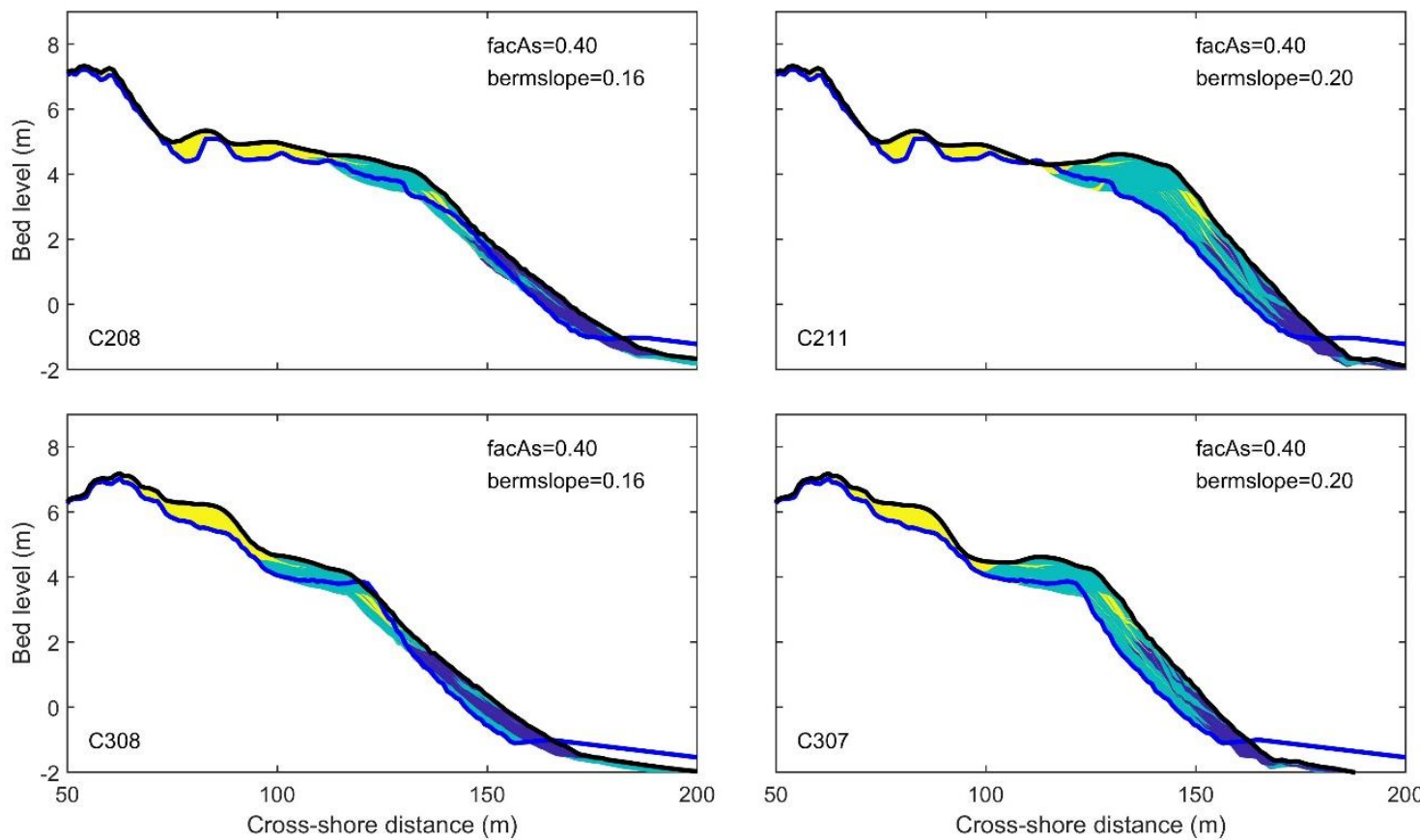

Figure 13. Calibration of profiles $P 2$ (top panels) and $P 3$ (bottom panels) for facAs=0.4 and bermslope of 0.16 (left panels) vs. 0.20 (right panels). Blue line: initial profile; black line: final profile. Colour indicate process responsible for deposition; yellow: dune, turquoise: storm, dark blue: moderate conditions.

The calibration of Duna was done using different combinations of mean grain-size, vegetation cover density and plant geometry parameter $(k)$ in order to reproduce not only the volume of sediment blown inland and retained within the dune, but also the resultant dune shape. In the first place, we wanted to allow the winds to transport as much sand as the observations documented. Therefore, we tested two mean grain-sizes; the first represents the mean of the beach $(500 \mu \mathrm{m})$ while the second would better represent the main fraction accumulated within the dunes $(350 \mu \mathrm{m})$. The latter showed better results with a greater amount of sand being transported inland as expected. We may question the use of only one sediment fraction as the reality shows a rather heterogeneous sediment distribution at the sediment source, but the application of supply limiting condition process is integrated here to include in a simple way the heterogeneous nature of the grain-size distribution. The value of $k$ tested ranged from 0.5 to 1.8 finding that the best value was around 0.9 , which had a significant impact on the wind velocity field but still allowing some sediment transference.

A more complex problem was the setting up of the appropriate vegetation cover, and in particular the best gradients in this parameter across the dune profile. After testing different solutions to define vegetation gradients between pre-defined discrete values, we have found that the best solution was setting up discrete values only at key elevations (i.e. the elevation at 
which ephemeral vegetation could already start colonization, where vegetation permanent vegetation starts, and finally where the maximum concentrations are attained) to avoid unnatural gradients. Having a good definition (based on ground-truthing observations) of the key elevations and vegetation gradients appears critical to obtain the desired shape of the dune, or in another words, to force the accumulation of blown sand as in the observation; e.g. the definition of a minimum elevation at which ephemeral vegetation could start colonizing was critical to prevent the bypassing of sand and even erosion of the beach backshore where otherwise a "valley of death" would be developed (Figure 14, Vegetation A). It is also important to note the importance of having smooth gradients to allow more realistic accumulation of sand across the dune as shown in Figure 14; Vegetation B vs C, which shows how a fraction of the sediment is retained within the stoss slope of the dune and less sediment reaches the inland dune ridge.

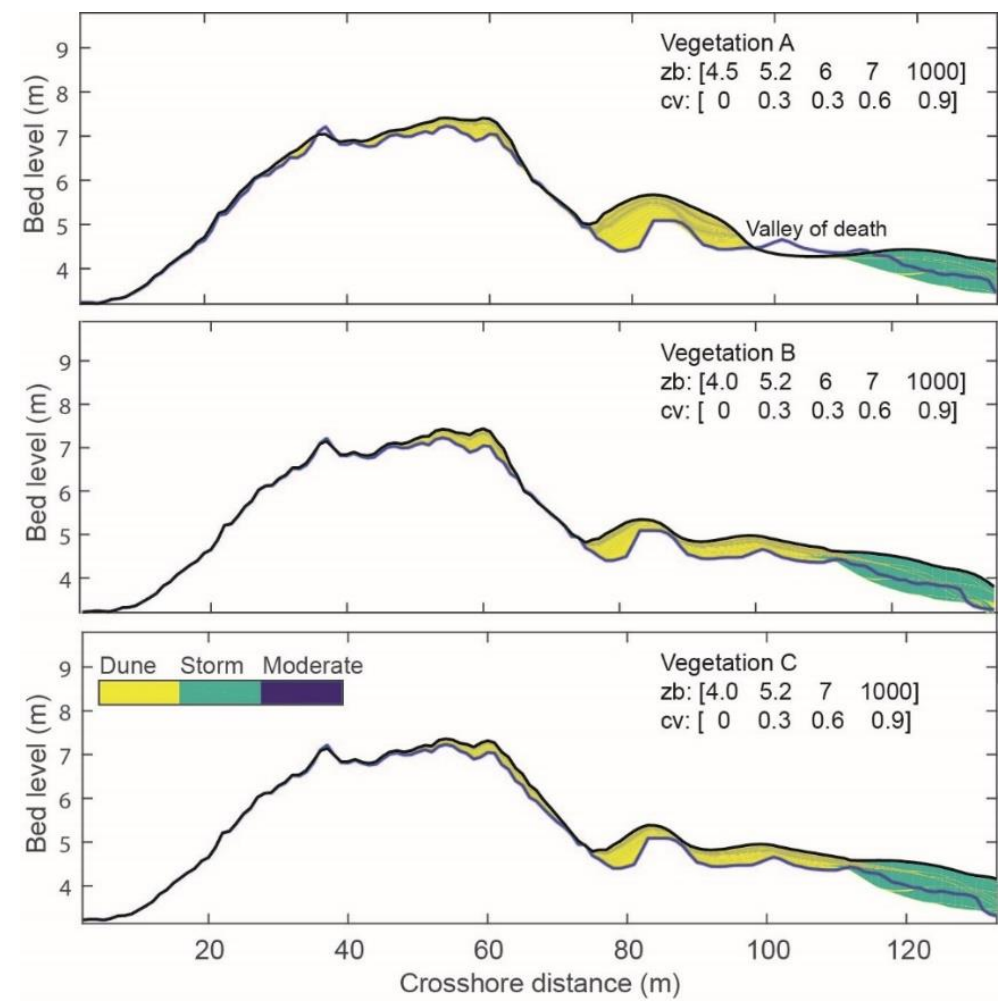

Figure 14. Effect of 3 different distributions of vegetation parameters. The colouring indicates the remaining stratigraphy, with colours indicating the process responsible for each deposited layer.

Overall, the chosen combination of parameters shows how the evolution of the steep profiles of Praia de Faro can be simulated over a period of two years with the results showing a fair reproduction of the intertidal beach profile, the dune and thus a good reproduction of the sediment exchange between the beach berms and the adjacent dune. In general terms, sediment accumulation within profile 2 occurred within the backshore profile, which is significantly greater that at profile 3 and where incipient dune ridges were developing before 2009. Conversely, accumulation of aeolian sand at profile 3 extended from the narrow backshore beach to the crest of the mature dune (Figure 13). 


\subsection{Short-term scenarios}

A series of short-term cases have been run to test the sensitivity of the model approach to changes in vegetation, the shape of the underwater profile, intensity of winds, and the occurrence of longshore gradients. In the latter case, we explore the different contributions to the bed level changes, due to longshore vs. cross-shore transports, and wave-driven vs. winddriven components

\subsubsection{Effect of vegetation}

The sensitivity of the model approach to the changes in vegetation was tested by comparing the resulting/calibrated profile 2 with a case where vegetation density was set to zero (Error! Reference source not found. top and middle panels). The test shows the role of the vegetation in holding in place the sediment and promoting the formation of small humps that may eventually turn into larger shapes, resembling the formation or initiation of hummocky dunes. In this regard, this test also shows how the lack of vegetation enhances the inland transference of sand from the emerged profile to the back of the mature dune ridge, promoting its eventual roll-over, and filling up any topographic lows. In this line, the results also show the importance of the embryo dune vegetation in promoting the vertical aggradation of the backshore, which otherwise would function as a bypass region.
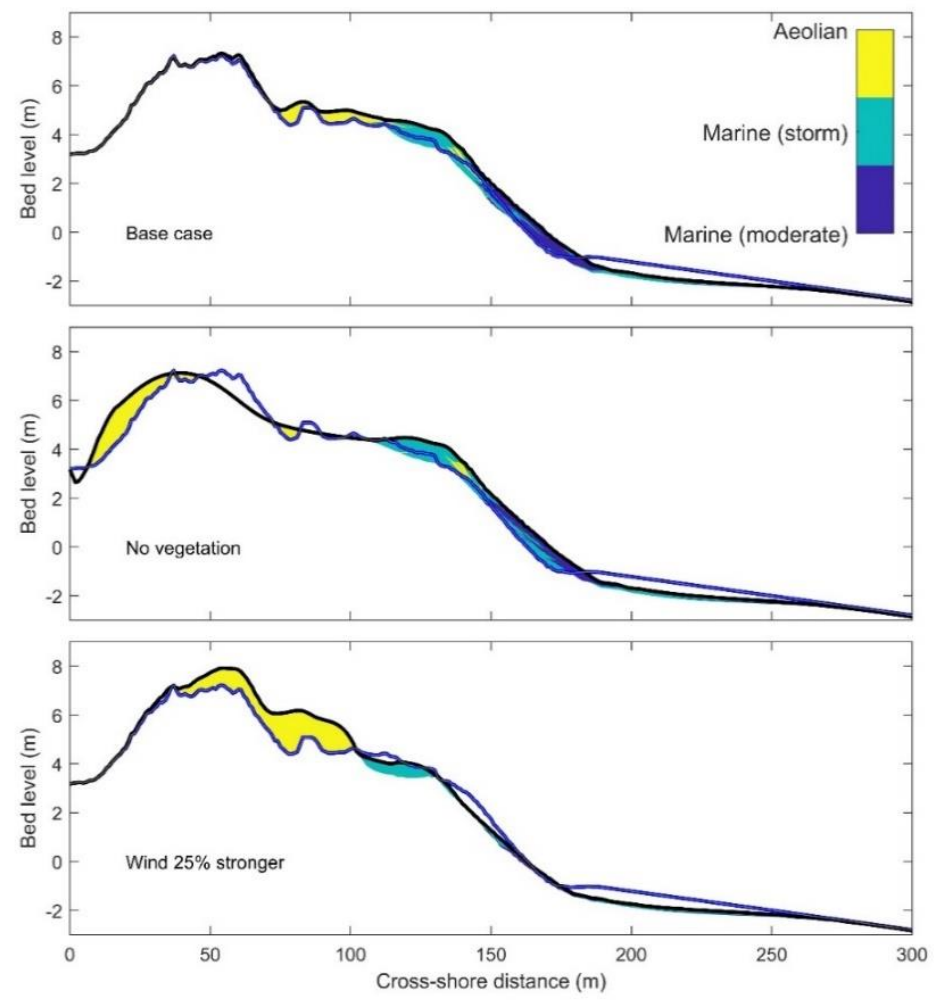

Figure 15. Base case simulation (top panel), vegetation left out (middle panel) and wind increased by 25\% (bottom panel). Initial profile: blue line; final profile: black line. Colours indicate process of deposition (yellow: dune; turquoise: storm; blue: moderate)

\subsubsection{Increased wind}

Changes in wind intensity have been tested as well using the same settings as for calibrated profile 2 . The test introduced a $25 \%$ increase on the wind intensity that doubled the volume of 
aeolian sediment transport from the upper beach towards the vegetated area of the profile, including a large part towards the mature dune ridge (Error! Reference source not

found.bottom panel). The latter seems to be encouraged because the reduction of the stronger winds by vegetation does not bring them below the threshold in this case.

\subsubsection{Longshore gradient effects}

Longshore transport gradients lead to accretion or erosion, which is then redistributed by cross-shore transport. To illustrate the behaviour and relative importance of this longshore transport gradient we carried out sensitivity runs over the same 2 years, with a gradient factor $\phi$ (XBeach keyword Isgrad) of $0.0002,0$ and $-0.0002 \mathrm{~m}^{-1}$. These numbers correspond to a length scale of longshore transport change of $5 \mathrm{~km}$. In case of a positive $\phi$, a positive transport leads to erosion; since our longshore transport is predominantly eastward and hence negative, a positive $\phi$ leads to accretion. The resulting bed evolution and bed level changes are depicted in Figure 16. The bed level changes due to different processes are shown in Figure 17, split into total, Duna, XBeach and the latter split into changes due to longshore and cross-shore gradients. As we see in these panels, cross-shore transport can keep up with the gradients, so the wave-dominated profile shape remains roughly constant, in line with assumptions in coastline theory; in the eroding case, however, the wind-dominated part lags behind: at this temporal scale and conditions, the sediment budget to the dune remains the same and is independent of the beach sediment budget.

In the accreting case we can most clearly see the stratigraphy resulting from the competing wind- and wave driven processes; we have coloured the deposited layers according to the responsible process, showing a competition between storms and wind events on the berm, and between moderate and storm conditions in the intertidal area. 

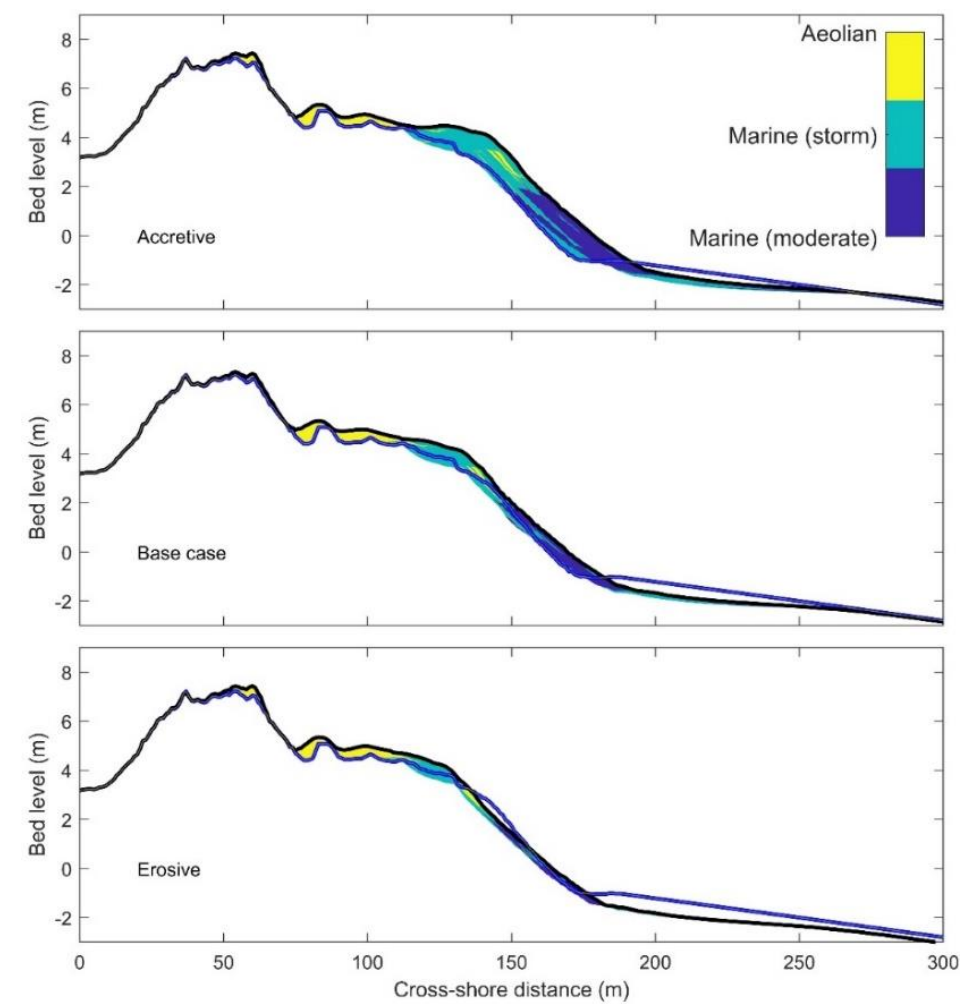

Figure 16. Profile evolution (blue line: initial; black line: final) and stratigraphy by deposition process (infilling colours). 

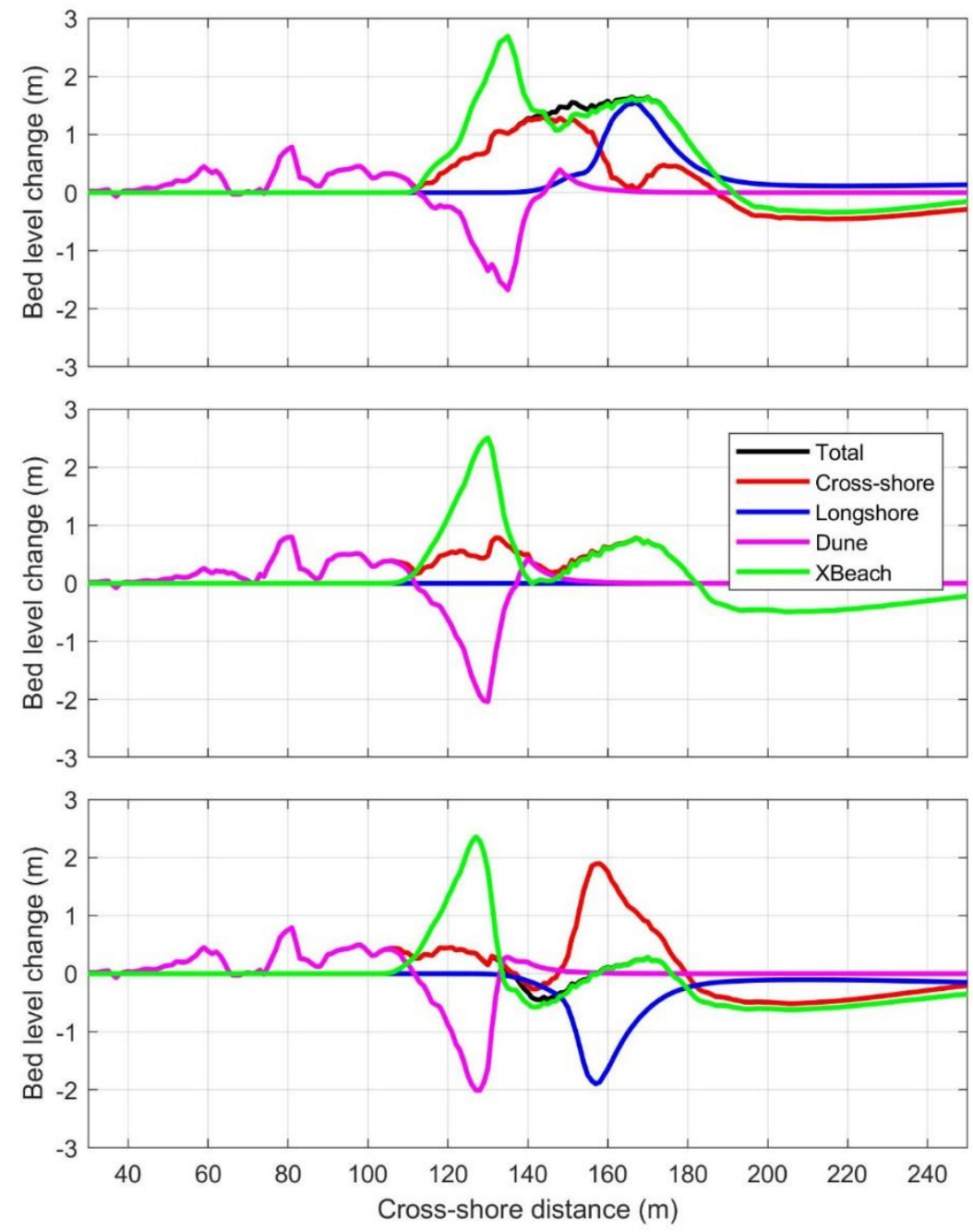

Figure 17. Contributions of different processes to bed level change (right panels), for a negative longshore gradient (top panel), zero gradient (middle panel) and positive gradient (bottom panel).

\subsubsection{Analysis of sediment budget and transport components}

Since we store the profiles after each event, we can separate out the contributions to the sediment budget by the different types of events. Especially in the case of the different longshore transport gradients a clear picture emerges, see Figure 17. The changes due to longshore transport gradients (in blue) predominantly take place in the intertidal area, and are to a large extent compensated by bottom changes due to cross-shore transport (in red). Changes in this area are mostly caused by the moderate conditions, as they are active here most of the time. On the other hand, there is a lively competition between the storm waves and the aeolian transport at the berm: the erosion by wind almost equals the deposition by storm waves. Interestingly, this balance hardly depends on the overall volume balance; the locus of the wind-wave battle just shifts seaward in the accreting case, relative to the erosive case. 


\section{Long-term scenarios}

We have seen that the sediment transport to the dune over a two-year period does not depend much on whether a profile is eroding or accreting. To see how this changes over longer time scales, we have extended the time period to 10 years, and increased the longshore gradient factor to $+/-0.0005 \mathrm{~m}^{-1}$. To see if we can recognize the seasonal patterns in the stratigraphic record we have simply repeated the 2-year time series 5 times. A detailed analysis of the effects of longer-term chronology and more realistic intra- and interannual variability is left for future work.

The results are shown in Figure 18. The grey lines indicate the profiles after each 2-year period. In the erosive case, the vegetation is attacked both by runup making it further up the profile and by the dune erosion during storms, which after some years now lead to scarping rather than berm building. This creates conditions for increased wind transport into the main dune, leading to the highest dune of all cases after 8 years, after which the sand is blown over the reducing dune. Continuation would lead to overwashing.

For the case without longshore gradients (middle panel) a new high foredune is created since the vegetation can develop sufficiently to trap most of the wind-blown transport. We also see that at this time scale the aeolian component is an important component and leads to sand loss in the intertidal area, where on the 2-year time scale the profile was mildly accreting.

The strongly accretive case shows a repeating signature in the intertidal area and swash berm. There is evidence of occasional aeolian deposition due to offshore winds, which would probably be difficult to find in reality. The foredune does not get the chance to develop anywhere as high as in the other simulations. In the beginning the upper beach is built up over the full width, but after approx. 5 years a new foredune starts building up, blocking more and more the transport to the original upper beach and dune. 

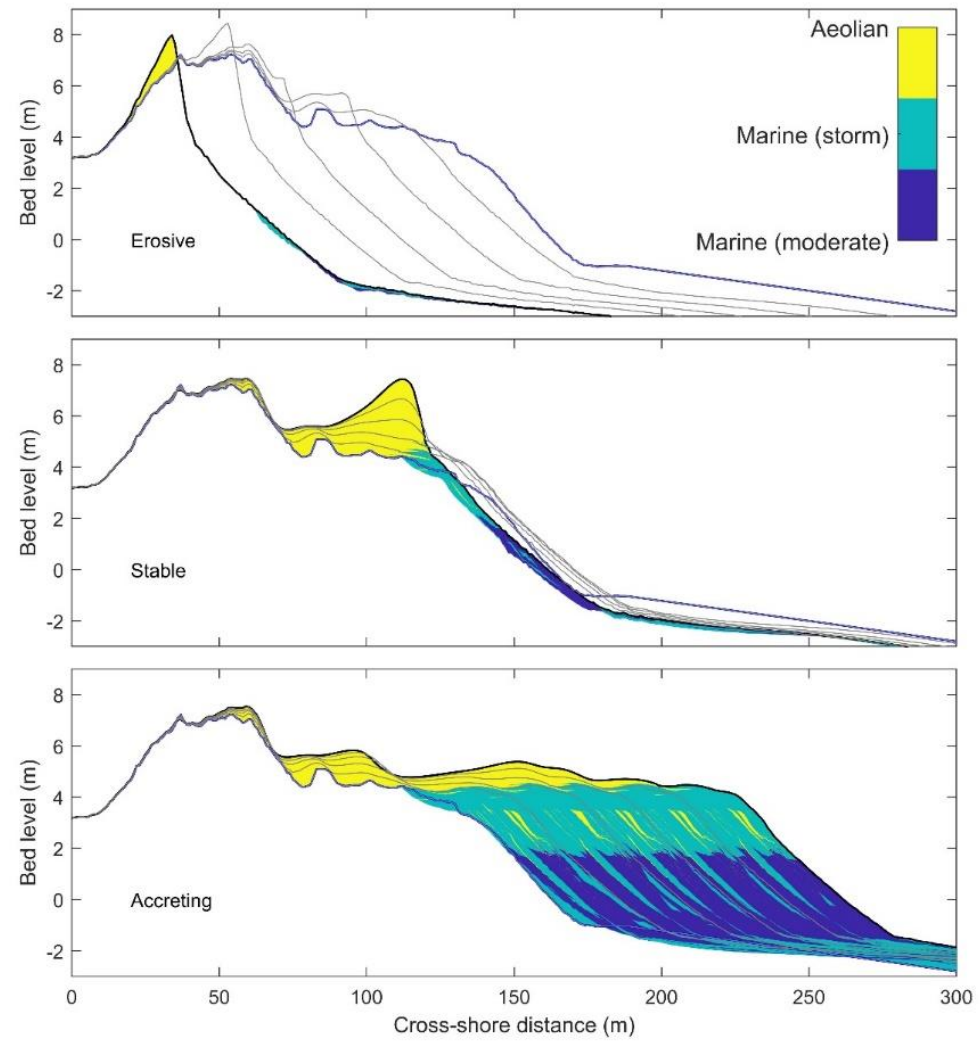

Figure 18. Profile and stratigraphy evolution over a 10-year period for a strongly erosive (top panel), approximately stable (middle panel) and strongly accretive case.

From these simulations the picture emerges of a continuum of morphological responses to environmental conditions as described by conceptual models (Arens, 1994; Hesp, 1999; Psuty, 1988) and summarized in Psuty (2004). We see that at this timescale and for the relatively constant conditions the underwater profile is mainly prograding or receding with a constant shape. We use this fact to simulate the whole range between strong progradation and recession using the Duna model only, with an adjustable supply rate that lets the wavedominated profile move back and forth. The Duna model was run with the same wind time series as before. Figure 19 shows the evolution of the dune profile under different recession/progradation rates. Though the patterns are smoother since there is no variability of the berm height, the emerging foredune patterns are quite similar to those with the full system, for the 3 cases shown before. We clearly see that a distinct new foredune is only created for mildly erosive to mildly accretive conditions, and that stronger progradation rates lead to a damping out of the foredune growth. For the particular wind, sediment and vegetation conditions of our case we do not see the development of clear multiple dune ridges. An extensive exploration of the conditions for creation of multiple dune ridges using our model is outside the scope of the present paper. What we do clearly see is the relation of the foredune height with the progradation rate, as is shown in Figure 20. The points in this Figure correspond with the blue dots in Figure 19. 

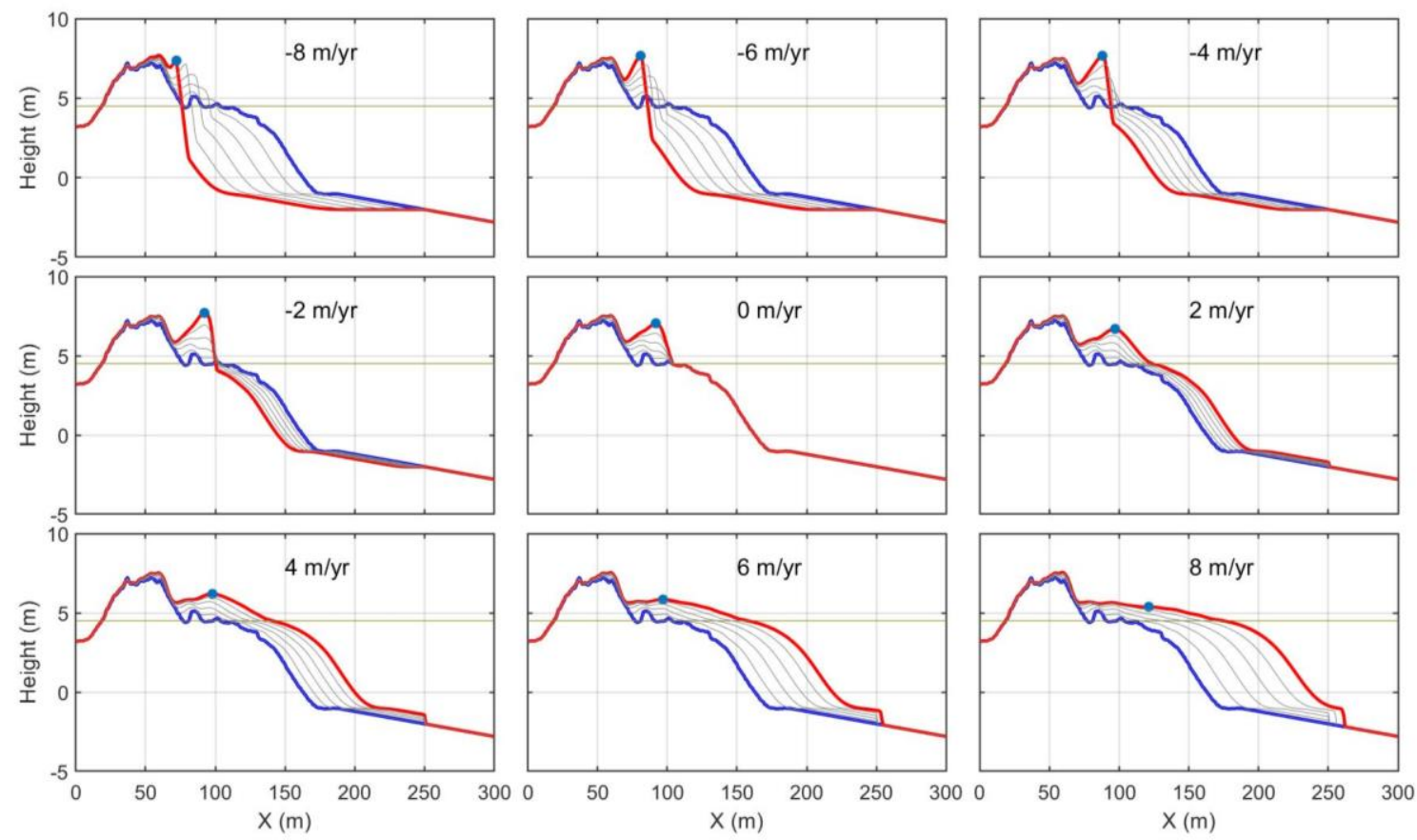

Figure 19. Dune development as a function of the progradation of the wave-dominated profile, between $-8 \mathrm{~m} / \mathrm{yr}$ and $+8 \mathrm{~m} / \mathrm{yr}$.

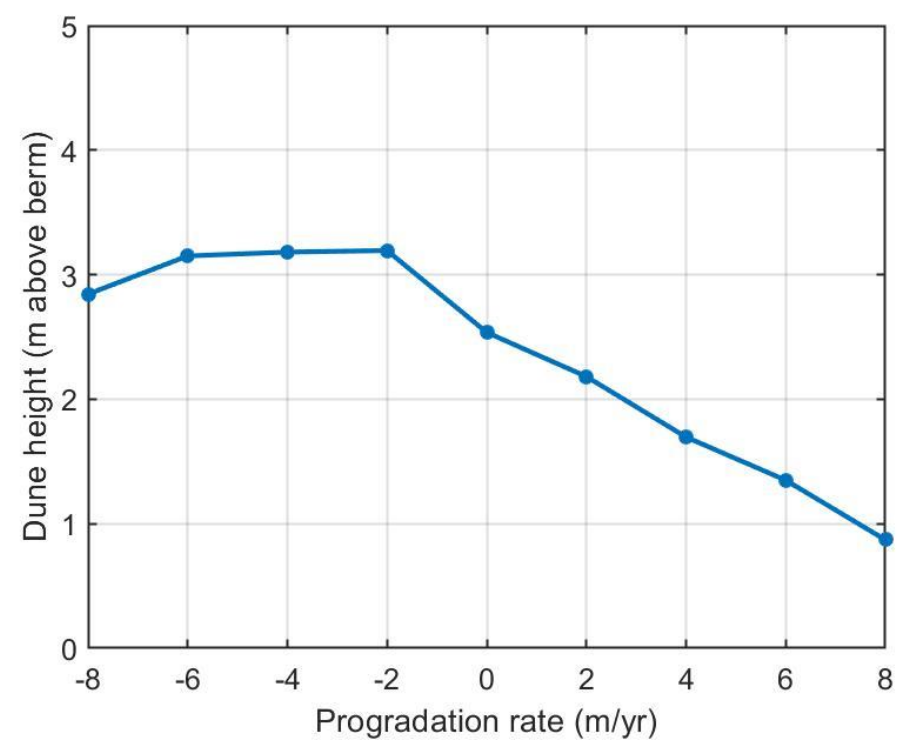

Figure 20. Foredune height as a function of beach progradation rate.

\section{Discussion}

Our model approach can be characterized as the simplest way to arrive at dune-beach behaviour at decadal timescales, while following a largely process-based approach. Both on the aerodynamic and on the hydrodynamic side we apply gross simplifications, but try to capture essential elements of the processes in both domains, to fill the gap between observations and modelling of detailed processes on short timescales, and biogeomorphological response on decadal timescales. For example, the wind model is the simplest possible model that will give a quantitatively reasonable approximation of the slowing down towards the dune foot, acceleration towards the crest and deceleration behind it. The 
wave-driven model, though relying on a heuristic fix to compensate for unresolved swash processes, now presents behaviour that is in agreement with observations (Almeida et al., 2011) and maintains reasonable profiles over years to decades. In the following we will discuss some important aspects in more detail.

A key issue when carrying out long-term simulations is the strategy applied to bridge the gap between short-term hydrodynamic and transport processes, varying over hours to days, and morphological changes, often taking place over much longer time periods (French et al., 2016; Murray, 2007; Roelvink, 2006). Several strategies have been proposed to overcome this limitation, including reduction techniques (i.e. input reduction, model reduction and simplification of processes), selection of representative conditions to investigate long-term morphodynamics (Benedet et al., 2016; de Vriend et al., 1993; Latteux, 1995), or bed level updating at each hydrodynamic time step to implement a feedback mechanism in the longterm (Ranasinghe et al., 2011; Roelvink, 2006). The strategy chosen here is based on 'input reduction', which has long been recognized as a way to reach longer timescales (e.g. de Vriend et al., 1993; Walstra et al., 2013) and applies schematized boundary conditions instead of real time series. The same approach could be applied also in forecast mode where the actual sequence of events is not known but where the long-term trend does not critically rely on this. Here, we have focused on generating series of conditions that have a clear seasonal variation and statistically represent moderate, storm and wind events. However, more sophisticated methods such as used in probabilistic shoreline recession models (e.g. Ranasinghe et al., 2012) could be applied here as well.

An important element of the processes in the aerodynamic domain that has been here carefully considered is the actual variable nature of the wind field. Our approach to oblique winds is fundamentally different from 2DV approaches in literature where the computation is carried out rotating the grids or using a profile oblique to the shoreline (Cohn, 2018; Hesp and Smyth, 2016a). In the latter case the assumption is that gradients in the direction normal to the transect are negligible, a condition that is violated for strongly oblique winds. In our approach, we assume that the relative distribution of the cross-shore component of the wind shear stress is not affected by the longshore wind stress, which may also be questionable but is in line with the general character of the wind model that the relative shear stress distribution depends solely on the dune topography. Our model approach predicts a variation in wind direction ('veering') over a linear dune system by approx. 15 relative to the incident direction, in line with field data and 3D CFD modelling as shown in Hesp et al. (2015).

The local wind field itself might be constantly modified by a range of factors, which in turn translates into sand transport intermittency and limits the straight forward application of standard equilibrium models of sand transport (Walker et al., 2017). In our approach, limiting factors have been introduced that locally modify the near-surface wind field (i.e. vegetation, slope, topography) or the threshold of motion (i.e. moisture, grain size, amoring) affecting directly the equilibrium transport. These lead to transparent formulations and behaviour, an important asset given the many factors involved in this complex system. The adjustment of transport to equilibrium is simulated through a simple but powerful approach. It uses a timescale for adaptation towards a (constantly changing) equilibrium; this timescale is currently prescribed but could be made a function of other parameters. Similar approaches have long been applied in river and coastal morphodynamic models, e.g. Galappatti and Vreugdenhil (1985), including in XBeach. The concept of 'fetch' is well captured in this approach, as is the effect of oblique wind on the fetch. For oblique winds, the cross-shore 
velocity is reduced as a fraction of the total wind speed; this reduces the length needed to reach equilibrium by the cosine of the direction as observed in the field (Bauer and DavidsonArnott, 2003; Davidson-Arnott and Dawson, 2001).

The vegetation itself is also included in our approach as a dynamic element. Though behaving according to a limited set of simple rules, the parameterization applied is realistic and based on observations that can be easily adapted to any site. A possible extension could be to include seasonality, for instance through an intra-annual shape function. We believe that a more complete population dynamics approach is possible in principle, comparable to models developed for salt marshes (e.g. Temmerman et al., 2005) or mangroves (e.g. Best et al., 2018). However, such models require much more detailed data on vegetation structure and behaviour, which is not easy to obtain.

Our simulations show a dependence of the foredune height on the rate of progradation of recession of the berm (see Section 5), as previously observed and included in conceptual models (Hesp, 1988; Hesp, 2013; Moore et al., 2016b; Psuty, 2004; Short and Hesp, 1982). According to these, the height of the foredune will be largely determined by the rate of shoreline change with stable shorelines showing the highest elevations. Though we did not explicitly look for it, nothing in our model appears to define a maximum dune height, conversely to the coastal dune model developed by Duran and Moore, but in agreement with the data-driven model by Davidson-Arnott et al. (2018). Probably the essential difference with the approach of Durán and Moore (2013) is that we do not explicitly make the vegetation a function of the distance from the shoreline but leave it to the balance between the destructive wave runup and scarping processes and the constructive vegetation growth. Furthermore, the oblique wind incidence allows almost longshore winds to pick up sand from the foot of the dune, which can then be transported by the cross-shore component (Hesp et al., 2015).

Application of the coupled XBeach-Duna model to different environments (e.g. more dissipative beaches, different grain size and vegetation characteristics, different wave climates) is an obvious next step, still limiting ourselves to linear dune systems. Extension to longshore variable topographies should then follow logically, which will involve the wind stress model by Weng et al. (1991) as applied in Durán and Moore (2013), but with modifications allowing an easy application for coastal dunes with oblique wind incidence. For the XBeach model, the 'bermslope' effect needs to be linked to physical parameters such as grain size, wave conditions and tidal range, and the representation of the behaviour of nearshore bars needs to be looked into. Finally, comparing model-simulated stratigraphies, generated using more realistic time series of forcing conditions, with those observed through Ground Penetrating Radar profiles and optical dating techniques should clear the way for longer-term simulations of effects of sea level rise and changes in wind and wave climate that go well beyond the Bruun rule. As simulations gradually capture more and more observed behaviour, we may eventually apply it to evaluate effects of future changes in coastal barrier systems and their forcings.

\section{Conclusions}

A new approach was developed to simulate the coupled beach-berm-dune system, forced by waves, wind and tides and strongly affected by vegetation growth and destruction. It can be applied on time scales from a single event to decades and shows a behaviour that is qualitatively well in line with observations at a semi-reflective beach and dune system. Two innovations in the existing XBeach model allow for a realistic intertidal beach slope and berm 
development on one hand, and erosion or accretion due to longshore transport gradients on the other hand; both features are essential to longer-term simulations. The simulations reveal an essential role for the beach berm, which is generated during storm events and then functions as a source of sand blown towards the dunes. As long as waves can overtop the berm they tend to build it up rather than destroy it; scarping takes place when the runup is below the berm crest or when the waves reach the dune front.

The dune model captures most mechanisms for linear dune systems discussed in literature and shows realistic responses to the parameters governing these mechanisms. It was shown to reproduce the amount and shape of upper beach and dune face accretion over a two-year period and to correctly reproduce the response of dune height to coastline accretion/recession rates. The model setup is such that individual processes can easily be modified or replaced and hence it has the potential to be used as a quantitative tool to simulate, evaluate and possibly predict dune behaviour.

\section{Acknowledgments}

The authors thank Puertos del Estado-AEMET, Spain, for providing the hindcast wave data and the Portuguese Institute for Sea and Atmosphere, I. P. (IPMA, IP) for providing wind data observations. Susana Costas is funded through the "FCT Investigator" program (ref. IF/01047/2014). This work is a contribution to the research project ENLACE (ref. 28949) supported by the Portuguese Science Foundation (FCT) through National and FEDER Funds and to the grant UID/MAR/00350/2013 supported by the Portuguese Science Foundation (FCT) and attributed to CIMA of the University of Algarve. The authors acknowledge the stimulating discussions on beach and dune model coupling in the informal WINDSURF group (Moore et al., 2016a).

\section{REFERENCES}

Almeida, L.P., Ferreira, Ó., Pacheco, A., 2011. Thresholds for morphological changes on an exposed sandy beach as a function of wave height. Earth Surface Processes and Landforms 36(4) 523-532.

Arens, S., 1994. Aeolian processes in the Dutch foredunes. Univ of Amsterdam: Amsterdam, p. 150.

Azizov, M.T., 1977. Influence of soil moisture on the resistance of soil to wind erosion. Pochvovedeniye 1 102-105.

Bagnold, R.A., 1936. The Movement of Desert Sand. Proceedings of the Royal Society of London. Series A - Mathematical and Physical Sciences 157(892) 594-620.

Bauer, B.O., Davidson-Arnott, R.G.D., 2003. A general framework for modeling sediment supply to coastal dunes including wind angle, beach geometry, and fetch effects. Geomorphology 49(1-2) 89-108.

Bauer, B.O., Davidson-Arnott, R.G.D., Hesp, P.A., Namikas, S.L., Ollerhead, J., Walker, I.J., 2009. Aeolian sediment transport on a beach: Surface moisture, wind fetch, and mean transport. Geomorphology 105(1) 106-116.

Belly, P.Y., 1964. Sand movement by wind, USACE Technical Memorandum 01. U.S. Army Corps Eng. CERC.: Washington, D.C., p. 38.

Benedet, L., Dobrochinski, J.P.F., Walstra, D.J.R., Klein, A.H.F., Ranasinghe, R., 2016. A morphological modeling study to compare different methods of wave climate 
schematization and evaluate strategies to reduce erosion losses from a beach nourishment project. Coastal Engineering 112 69-86.

Best, Ü.S.N., Van der Wegen, M., Dijkstra, J., Willemsen, P.W.J.M., Borsje, B.W., Roelvink, D.J.A., 2018. Do salt marshes survive sea level rise? Modelling wave action, morphodynamics and vegetation dynamics. Environmental Modelling \& Software 109 152-166.

Buckley, R., 1987. The effect of sparse vegetation on the transport of dune sand by wind. Nature 325426.

Cohn, N.T., 2018. From the Shoreface to the Foredunes : Coastal Morphodynamics Across the Land-Sea Interface. Oregon State University.

Costa, M., Silva, R., Vitorino, J., 2001. Contribuição para o estudo do clima de agitação marítima na costa Portuguesa, II Jornadas Portuguesas de Engenharia Costeira e Portuária: Sines, Portugal

Costas, S., Bom de Sousa, L., Plomaritis, T.A., Pliatsika, D.A., Ferreira, O., 2017. Aeolian sediment transport enhanced by storms and human pressure at coarse sandy barrier islands, In: Buades, G.P., Lorenzo-Lacruz, J., Pujol, L.G. (Eds.), IX Jornadas de Geomorfología Litoral. Geo-Temas: Menorca Spain, pp. 301-306.

Costas, S., Ramires, M., de Sousa, L.B., Mendes, I., Ferreira, O., 2018. Surficial sediment texture database for the south-western Iberian Atlantic margin. Earth Syst. Sci. Data 10(2) 11851195.

Davidson-Arnott, R., Hesp, P., Ollerhead, J., Walker, I., Bauer, B., Delgado-Fernandez, I., Smyth, T., 2018. Sediment Budget Controls on Foredune Height: Comparing Simulation Model Results with Field Data. Earth Surface Processes and Landforms n/a-n/a.

Davidson-Arnott, R.G.D., Bauer, B.O., 2009. Aeolian sediment transport on a beach: Thresholds, intermittency, and high frequency variability. Geomorphology 105(1-2) 117-126.

Davidson-Arnott, R., Dawson, J., 2001. Moisture and fetch effects on rates of aeolian sediment transport, Skallingen, Denmark, Canadian Coastal Conference. CCSEA: Quebec City, pp. 309-321.

de Vriend, H.J., Capobianco, M., Chesher, T., de Swart, H.E., Latteux, B., Stive, M.J.F., 1993. Approaches to long-term modelling of coastal morphology: A review. Coastal Engineering 21(1) 225-269.

de Vries, S., van Thiel de Vries, J.S.M., van Rijn, L.C., Arens, S.M., Ranasinghe, R., 2014. Aeolian sediment transport in supply limited situations. Aeolian Research 12(0) 75-85.

Delgado-Fernandez, I., 2010. A review of the application of the fetch effect to modelling sand supply to coastal foredunes. Aeolian Research 2(2) 61-70.

Delgado-Fernandez, I., 2011. Meso-scale modelling of aeolian sediment input to coastal dunes. Geomorphology 130(3-4) 230-243.

Durán, O., Herrmann, H.J., 2006. Vegetation Against Dune Mobility. Physical Review Letters 97(18) 188001.

Durán, O., Moore, L.J., 2013. Vegetation controls on the maximum size of coastal dunes. Proceedings of the National Academy of Sciences 110(43) 17217-17222.

French, J., Payo, A., Murray, B., Orford, J., Eliot, M., Cowell, P., 2016. Appropriate complexity for the prediction of coastal and estuarine geomorphic behaviour at decadal to centennial scales. Geomorphology 256 3-16.

Galappatti, G., Vreugdenhil, C.B., 1985. A depth-integrated model for suspended sediment transport. Journal of Hydraulic Research 23(4) 359-377. 
Hanson, H., Larson, M., Kraus, N.C., 2010. Calculation of beach change under interacting crossshore and longshore processes. Coastal Engineering 57(6) 610-619.

Hesp, P., 1988. Morphology, dynamics and internal stratification of some established foredunes in southeast Australia. Sedimentary Geology 55(1-2) 17-41.

Hesp, P.A., 1999. The beach backshore and beyond, In: Short, A.D. (Ed.), Handbook of Beach and Shoreface Morphodynamics. John Wiley and Sons: NewYork, pp. 145-169.

Hesp, P.A., 2013. A 34 year record of foredune morphodynamics at Dark Point, NSW, Australia, In: Conley, D.C., Masselink, G., Russell, P.E., O'Hare, T.J. (Eds.), 12th International Coastal Symposium Journal of Coastal Research: Plymouth, England, pp. 1295-1300.

Hesp, P.A., Smyth, T.A.G., 2016a. Jet flow over foredunes. Earth Surface Processes and Landforms 41(12) 1727-1735.

Hesp, P.A., Smyth, T.A.G., 2016b. Surfzone-Beach-Dune interactions: Flow and Sediment Transport across the Intertidal Beach and Backshore. Journal of Coastal Research 8-12.

Hesp, P.A., Smyth, T.A.G., 2017. Nebkha flow dynamics and shadow dune formation. Geomorphology 282 27-38.

Hesp, P.A., Smyth, T.A.G., Nielsen, P., Walker, I.J., Bauer, B.O., Davidson-Arnott, R., 2015. Flow deflection over a foredune. Geomorphology 230 64-74.

Hesp, P.A., Walker, I.J., Chapman, C., Davidson-Arnott, R., Bauer, B.O., 2013. Aeolian dynamics over a coastal foredune, Prince Edward Island, Canada. Earth Surface Processes and Landforms 38(13) 1566-1575.

Hoonhout, B.M., de Vries, S., 2016. A process-based model for aeolian sediment transport and spatiotemporal varying sediment availability. Journal of Geophysical Research: Earth Surface 121(8) 1555-1575.

Hoonhout, B.M., Vries, S.d., 2016. A process-based model for aeolian sediment transport and spatiotemporal varying sediment availability. Journal of Geophysical Research: Earth Surface 121(8) 1555-1575.

Horikawa, K., Watanabe, A., Katori, S., 1982. Sediment transport under sheet flow conditions, 18th International Conference on Coastal Engineering. ASCE, pp. 1335-1352.

Hotta, S., Kubota, S., Katori, S., Horikawa, K., 1985. Sand Transport by Wind on a Wet Sand Surface, Coastal Engineering 1984, 2011-01-29 ed.

Houser, C., 2009. Synchronization of transport and supply in beach-dune interaction. Progress in Physical Geography 33(6) 733-746.

Iversen, J.D., Rasmussen, K.R., 1999. The effect of wind speed and bed slope on sand transport. Sedimentology 46(4) 723-731.

Johnson, J.W., 1963. Sand movement on coastal dunes. CALIFORNIA UNIV BERKELEY HYDRAULIC ENGINEERING LAB, p. 22.

Keijsers, J.G.S., De Groot, A.V., Riksen, M.J.P.M., 2016. Modeling the biogeomorphic evolution of coastal dunes in response to climate change. Journal of Geophysical Research: Earth Surface 121(6) 1161-1181.

Kroy, K., Sauermann, G., Herrmann, H.J., 2002. Minimal Model for Sand Dunes. Physical Review Letters 88(5) 054301.

Larson, M., Kraus, N.C., 1989. SBEACH: Numerical Model for Simulating Storm-Induced Beach Change. Report 1. Empirical Foundation and Model Development. COASTAL ENGINEERING RESEARCH CENTER VICKSBURG MS, p. 266.

Larson, M., Kraus, N.C., 1991. Mathematical Modeling of the Fate of Beach Fill. Coastal Engineering 16(1) 83-114. 
Larson, M., Palalane, J., Fredriksson, C., Hanson, H., 2016. Simulating cross-shore material exchange at decadal scale. Theory and model component validation. Coastal Engineering 116 57-66.

Latteux, B., 1995. Techniques for long-term morphological simulation under tidal action. Marine Geology 126(1) 129-141.

Logie, M., 1982. Influence of roughness elements and soil moisture of sand to wind erosion. Catena Supplement 1 161-173.

Moore, L.J., Roelvink, J.A., Ruggiero, P., Cohn, N., Hoonhout, B., Vinent, O.D., Goldstein, E.B., Vries, S.d., 2016a. Crossing the Shoreline Divide: Toward modeling the co-evolution of dune, beach and nearshore systems, Ocean Sciences Meeting 2016. American Geophysical Union: New Orleans, Louisiana, pp. MG14A-1921.

Moore, L.J., Vinent, O.D., Ruggiero, P., 2016b. Vegetation control allows autocyclic formation of multiple dunes on prograding coasts. Geology 44(7) 559-562.

Murray, A.B., 2007. Reducing model complexity for explanation and prediction. Geomorphology 90(3-4) 178-191.

Pender, D., Karunarathna, H., 2013. A statistical-process based approach for modelling beach profile variability. Coastal Engineering 81 19-29.

Poelhekke, L., Jäger, W.S., van Dongeren, A., Plomaritis, T.A., McCall, R., Ferreira, Ó., 2016. Predicting coastal hazards for sandy coasts with a Bayesian Network. Coastal Engineering 118 21-34.

Psuty, N.P., 1988. SEDIMENT BUDGET AND DUNE/BEACH INTERACTION. Journal of Coastal Research 1-4.

Psuty, N.P., 2004. The coastal foredune: a morphological basis for regional coastal dune development, In: ML, M., NP, P. (Eds.), Coastal dunes, ecology and conservation. . Springer-Verlag: Berlin, pp. 11-27.

Ranasinghe, R., Callaghan, D., Stive, M.J.F., 2012. Estimating coastal recession due to sea level rise: beyond the Bruun rule. Climatic Change 110(3) 561-574.

Ranasinghe, R., Swinkels, C., Luijendijk, A., Roelvink, D., Bosboom, J., Stive, M., Walstra, D., 2011. Morphodynamic upscaling with the MORFAC approach: Dependencies and sensitivities. Coastal Engineering 58(8) 806-811.

Roelvink, D., Costas, S., 2017. Beach berms as an essential link between subaqueous and subaerial beach/dune profiles. Geo-Temas 17 79-82.

Roelvink, D., McCall, R., Mehvar, S., Nederhoff, K., Dastgheib, A., 2018. Improving predictions of swash dynamics in XBeach: The role of groupiness and incident-band runup. Coastal Engineering 134 103-123.

Roelvink, D., Reniers, A., van Dongeren, A., van Thiel de Vries, J., McCall, R., Lescinski, J., 2009. Modelling storm impacts on beaches, dunes and barrier islands. Coastal Engineering 56(11-12) 1133-1152.

Roelvink, J.A., 2006. Coastal morphodynamic evolution techniques. Coastal Engineering 53(23) 277-287.

Ruessink, B.G., Kuriyama, Y., Reniers, A.J.H.M., Roelvink, J.A., Walstra, D.J.R., 2007. Modeling cross-shore sandbar behavior on the timescale of weeks. J. Geophys. Res. 112(F3) F03010.

Sauermann, G., Kroy, K., Herrmann, H.J., 2001. Continuum saltation model for sand dunes. Physical Review E 64(3) 031305.

Sherman, D.J., Bauer, B.O., 1993. Dynamics of beach-dune systems. Progress in Physical Geography: Earth and Environment 17(4) 413-447. 
Short, A.D., Hesp, P.A., 1982. Wave, beach and dune interactions in southeastern Australia. Marine Geology 48(3) 259-284.

Smith, A.B., Jackson, D.W.T., Cooper, J.A.G., 2017a. Three-dimensional airflow and sediment transport patterns over barchan dunes. Geomorphology 278 28-42.

Smith, A.B., Jackson, D.W.T., Cooper, J.A.G., Hernández-Calvento, L., 2017b. Quantifying the role of urbanization on airflow perturbations and dunefield evolution. Earth's Future 5(5) 520-539.

Smyth, T.A.G., Jackson, D.W.T., Cooper, J.A.G., 2013. Three dimensional airflow patterns within a coastal trough-bowl blowout during fresh breeze to hurricane force winds. Aeolian Research 9 111-123.

Stive, M.J.F., Schipper, M.A.d., Luijendijk, A.P., Aarninkhof, S.G.J., Gelder-Maas, C.v., Vries, J.S.M.v.T.d., Vries, S.d., Henriquez, M., Marx, S., Ranasinghe, R., 2013. A New Alternative to Saving Our Beaches from Sea-Level Rise: The Sand Engine. Journal of Coastal Research 1001-1008.

Temmerman, S., Bouma, T.J., Govers, G., Wang, Z.B., De Vries, M.B., Herman, P.M.J., 2005. Impact of vegetation on flow routing and sedimentation patterns: Three-dimensional modeling for a tidal marsh. Journal of Geophysical Research: Earth Surface 110(F4).

Tsoar, H., Zohar, Y., 1985. Desert dune sand and its potential for modern agricultural development, In: Gradus, Y. (Ed.), Desert Development. Reidel: Dordrecht, pp. 184-200.

van Boxel, J.H., Arens, S.M., van Dijk, P.M., 1999. Aeolian processes across transverse dunes. I: Modelling the air flow. Earth Surface Processes and Landforms 24(3) 255-270.

van Dijk, P.M., Arens, S.M., van Boxel, J.H., 1999. Aeolian processes across transverse dunes. II: modelling the sediment transport and profile development. Earth Surface Processes and Landforms 24(4) 319-333.

Vousdoukas, M.I., Almeida, L.P.M., Ferreira, Ó., 2012. Beach erosion and recovery during consecutive storms at a steep-sloping, meso-tidal beach. Earth Surface Processes and Landforms 37(6) 583-593.

Walker, I.J., Davidson-Arnott, R.G.D., Bauer, B.O., Hesp, P.A., Delgado-Fernandez, I., Ollerhead, J., Smyth, T.A.G., 2017. Scale-dependent perspectives on the geomorphology and evolution of beach-dune systems. Earth-Science Reviews.

Walstra, D.J.R., Hoekstra, R., Tonnon, P.K., Ruessink, B.G., 2013. Input reduction for long-term morphodynamic simulations in wave-dominated coastal settings. Coastal Engineering 77 57-70.

Walstra, D.J.R., Reniers, A.J.H.M., Ranasinghe, R., Roelvink, J.A., Ruessink, B.G., 2012. On bar growth and decay during interannual net offshore migration. Coastal Engineering 60 190-200.

Weng, W.S., Hunt, J.C.R., Carruthers, D.J., Warren, A., Wiggs, G.F.S., Livingstone, I., Castro, I., 1991. Air flow and sand transport over sand-dunes, In: Barndorff-Nielsen, O.E., Willetts, B.B. (Eds.), Aeolian Grain Transport. Springer: Vienna, pp. 1-22. 